\title{
Energy Conversion Routes in the Western Mediterranean Sea Estimated from Eddy-Mean Flow Interactions
}

\author{
ESTHER CAPÓ AND ALEJANDRO ORFILA \\ IMEDEA (Spanish National Research Council-University of the Balearic Islands), Esporles, Spain \\ EVAN MASON \\ IMEDEA (Spanish National Research Council-University of the Balearic Islands), Esporles, \\ Spain, and Applied Physics Laboratory, University of Washington, Seattle, Washington \\ SIMÓN RUIZ \\ IMEDEA (Spanish National Research Council-University of the Balearic Islands), Esporles, Spain
}

(Manuscript received 7 March 2018, in final form 8 November 2018)

\begin{abstract}
Energy conversion routes are investigated in the western Mediterranean Sea from the eddy-mean flow interactions. The sources of eddy kinetic energy are analyzed by applying a regional formulation of the Lorenz energy cycle to 18 years of numerical simulation at eddy-resolving resolution $(3.5 \mathrm{~km})$, which allows for identifying whether the energy exchange between the mean and eddy flow is local or nonlocal. The patterns of energy conversion between the mean and eddy kinetic and potential energy are estimated in three subregions of the domain: the Alboran Sea, the Algerian Basin, and the northern basin. The spatial characterization of the energy routes hints at the physical mechanisms involved in maintaining the balance, suggesting that flow-topography interaction is strongly linked to eddy growth in most of the domain.
\end{abstract}

\section{Introduction}

Ocean circulation in the western Mediterranean Sea (WMed; acronyms are defined in appendix A) is governed by processes within a broad range of time and spatial scales, from the basin-scale long-term thermohaline circulation to the short-lived small-scale eddies and meanders of the order of few kilometers or less. Its location and complicated bathymetric configuration sets the mesoscale limit, defined by the Rossby radius of deformation, between 5 and $15 \mathrm{~km}$ depending on the area and time of the year considered. The corresponding upper limit for mesoscale processes cannot be accurately determined and is usually defined, in terms of temporal duration, to be smaller than the scale of the principal currents (Beuvier et al. 2012; Escudier et al. 2016). At larger scales, $O(100) \mathrm{km}$, satellite observations have revealed interannual variability components in the mean currents as well as in the semipermanent mesoscale structures that do not seem to correlate with

Corresponding author: Esther Capó, ecapo@imedea.uib-csic.es external forcings but rather result from internal dynamics (Pinardi and Masetti 2000; Pujol and Larnicol 2005; Mason and Pascual 2013; Malanotte-Rizzoli et al. 2014). Recent studies in ocean (sub)mesoscale processes have shown increasing evidence of the interactions among the different scales. This is rather obvious when considering processes in terms of the energy balance: while most of the energy input from the atmosphere is absorbed by large-scale currents, the necessary dissipation required to maintain balance takes place at molecular scales. Between these extremes, a broad variety of mesoscale and submesoscale processes necessarily occur to set the pathways toward reaching energy equilibrium.

In the ocean, kinetic energy (KE) is mostly concentrated in the time-varying flow, while the potential energy (PE) is stored in the mean circulation. The Lorenz energy cycle (LEC) is an effective tool for providing a quantitative assessment of the energy generation, dissipation, and conversion terms among the different energy forms. The LEC was first implemented in the atmosphere by Lorenz (1955), who proposed the study of the energy cycle based on the description of the 


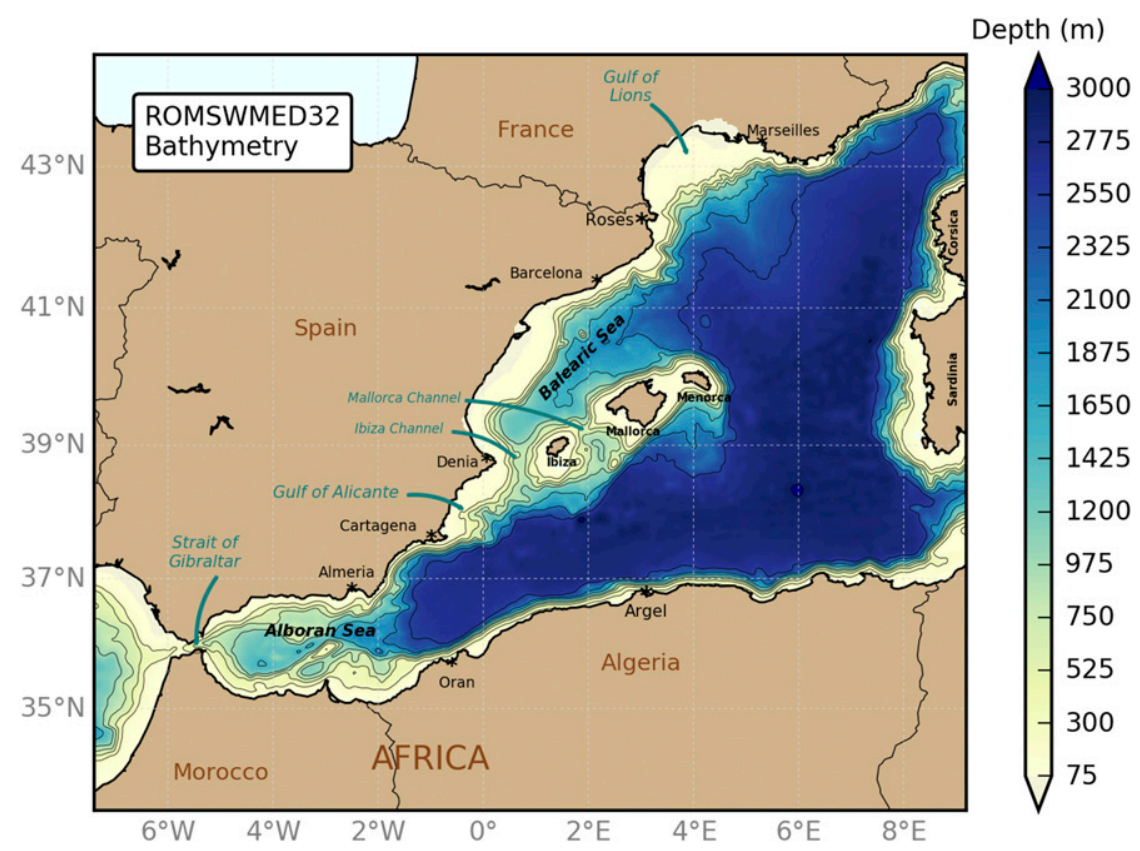

FIG. 1. ROMSWMED32 simulation domain, bathymetry (color bar), and locations of interest. Black contours represent 250-, 500-, 750-, 1000-, 1500-, 2000-, 2500-, and 3000-m isobaths.

steady-state balance of the four basic energy reservoirs: the KE and the available PE of the mean flow and of the time-varying circulation. For oceanic turbulent flows, Harrison and Robinson (1978) presented a pioneer work involving an exhaustive analysis of the the LEC from a numerical ocean circulation experiment; Oort et al. (1994) addressed the problem of the large-scale energetics for the global ocean from a variety of ocean surface observations and, more recently, von Storch et al. (2012) provided an estimate of the LEC for the World Ocean derived from a $1 / 10^{\circ}$ numerical simulation.

Available observational datasets still remain too spread in space and time and cannot be used to study the energy conversion pathways between the mean and time-varying flow. In this regard, numerical models perform realistic simulations long enough to achieve a statistically stationary state of the ocean so that dynamics can be investigated from the analysis of energy budgets involved in the balance equations.

The goal of this study is to estimate the LEC in the WMed from a 18-yr model simulation at eddy-resolving resolution $(3.5 \mathrm{~km})$ and to use it to identify the physical mechanisms responsible for maintaining the energy balance (Marchesiello et al. 2003; Sorgente et al. 2011; Renault et al. 2016; Wu et al. 2017).

\section{Analysis region}

The Mediterranean Sea is a large semienclosed basin extending between $30^{\circ}$ and $45^{\circ} \mathrm{N}$ and between $6^{\circ} \mathrm{E}$ and $37^{\circ} \mathrm{W}$. It can be divided into two parts, the eastern and western subbasins, separated by the Strait of Sicily, a channel about $145 \mathrm{~km}$ wide and with a maximum depth of $316 \mathrm{~m}$, which constrains the flow from one side to the other as well as water properties and dynamics. On the western edge, the Strait of Gibraltar constitutes the unique gateway to the Atlantic Ocean through which water exchange between both basins takes place. The strait's narrowest point is $14.3 \mathrm{~km}$ wide, while depth ranges between 300 and $900 \mathrm{~m}$ (Fig. 1).

The region has a complex topography including high mountains, numerous peninsulas, capes, and a myriad of islands of many different shapes and sizes depicting a complicated bathymetry, which, in conjunction with atmospheric and internal forcings (mainly wind stress and buoyancy fluxes driven by heat and water fluxes at the surface) inevitably condition the dynamical behavior. As a result, circulation is characterized by processes covering a broad range of interacting scales (Fig. 2). The Mediterranean thermohaline circulation is the main large-scale feature. Going down through the scales, there are quasi-permanent and variable boundary currents, jets, meanders and ring vortices, permanent mesoscale cyclonic and anticyclonic gyres, and energetic submesoscale eddies (Millot 1999; Pinardi and Masetti 2000; Robinson et al. 2001). The lower limit for the horizontal scales at which mesoscale processes occur is given by the first baroclinic Rossby radius of deformation $R_{1}$, which can be estimated as 


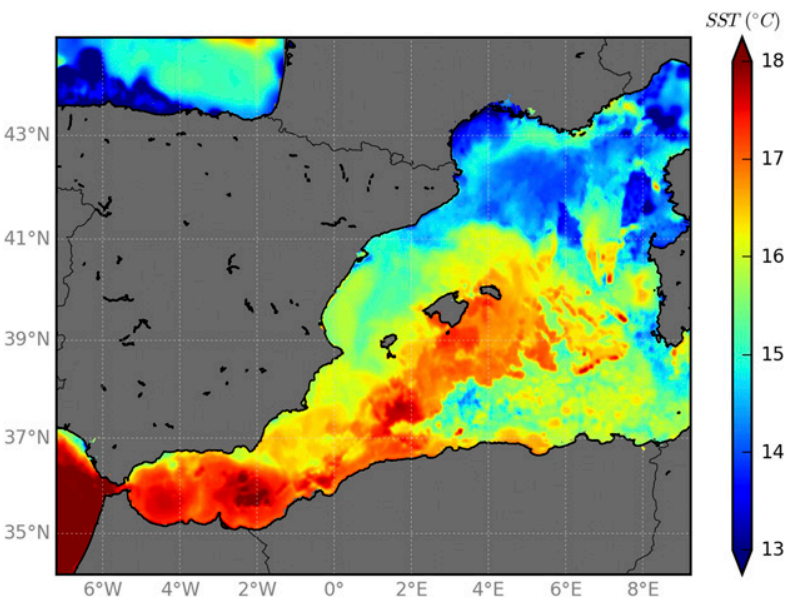

FIG. 2. Snapshot of sea surface temperature on 5 Jan 2013 for the western Mediterranean Sea at 1-km resolution (from the L4 gridded product provided in GHRSST)

$$
R_{1} \approx \frac{\int_{-H}^{0} N(z) d z}{\pi|f|},
$$

where $H$ represents the column depth, $f$ is the Coriolis parameter, and $N(z)$ is the Brunt-Väisälä frequency (Chelton et al. 1998). Values derived from our simulation show a marked seasonal variability, with the minimum and maximum amounts registered in February and August, respectively. The regional characterization displays the lowest values (4-9 km, from winter to summer) in the area of the Gulf of Lions, while the major scales (13$17 \mathrm{~km})$ are typical in the south. Besides the decrease of $R_{1}$ with latitude expected from its inverse proportionality with the Coriolis parameter $f$, this north-south gradient is also consistent with the fact that stratification is much weaker in the northern regions (e.g., Gulf of Lions), which are affected by wind-induced mixing in winter.

The paper is organized as follows. Model simulation and methods are presented in section 2 . To perform the energy analysis, first, the concepts of mean (eddy) kinetic energy and mean (eddy) available potential energy are introduced. Then, the Lorenz energy cycle considered in terms of ocean dynamics is presented, using the energy balance equations derived in Chen et al. (2014), and the terms involved in eddy kinetic energy production are identified for further analysis. Results are presented in section 3: seasonal and regional characterization of the mean (mesoscale) circulation is supported by the analysis of eddy kinetic energy variability. Estimation of the LEC and the spatial distribution of the conversion rates among different forms of energy is assessed in three subregions of the domain. The results are summarized and discussed in section 4 .

\section{Methods}

\section{a. Model configuration}

An 18-yr simulation from the Regional Ocean Modeling System (ROMS) Shchepetkin and McWilliams 2005) in its Adaptive Grid Refinement in Fortran (AGRIF), version 3.0 (Debreu et al. 2008), developed in a previous work by Escudier (2015), provides the data used in this study (ROMSWMED32). ROMS-AGRIF is a 3D freesurface, terrain-following coordinate model that solves the primitive equations for momentum, temperature, and salinity using the hydrostatic and Boussinesq approximations. A multiple-time-level time stepping allows for solving both barotropic and baroclinic dynamics, occurring at different time scales. Vertical mixing of momentum and tracers is parameterized using the nonlocal $K$-profile parameterization (KPP) scheme by Large-McWilliamsDoney (LMD) (Large et al. 1994). Bathymetry was obtained by combining the one developed by Smith and Sandwell (1997) and a more detailed representation for the Gibraltar region (Sanz et al. 1991). Horizontal advection is parameterized using a third-order upstreambiased scheme for momentum and tracers, performing the necessary adjustments to reduce diapycnal mixing. A realistic initial state of the ocean interior and boundary conditions was achieved using a 55-yr simulation of a configuration of NEMO in the WMed region (NEMOMED12) over the period 1958-2013 covering the entire Mediterranean with a $1 / 12^{\circ}$ resolution. The atmospheric forcing is given by the NCEP-CFSR dataset, with a $35-\mathrm{km}$ spatial resolution and a time step of $6 \mathrm{~h}$, using a bulk formulation for fluxes.

The vertical grid is composed of $32 \sigma$ levels using the vertical stretching function defined in Shchepetkin and McWilliams (2009) with stretching parameters $\theta_{s}=6.5$ and $\theta_{b}=1.5$ at the surface and bottom, respectively; and a critical depth $h_{c}=250 \mathrm{~m}$, which implies upper-level sizes ranging from 2 to $7.5 \mathrm{~m}$ and from 4 to $280 \mathrm{~m}$ at the bottom. The stretching range at the surface permits enough resolution in the upper levels to resolve mesoscale dynamics, although the low resolution in the bottom layers must be taken into consideration when interpreting results regarding energy budget analysis.

Because ROMSWMED32 is a new implementation of ROMS in the WMed region, an exhaustive validation is performed in Escudier (2015). Here we summarize some aspects from this validation that are relevant for the present study. First, the mean surface circulation of the western Mediterranean Sea is well reproduced in ROMSWMED32 when compared with the mean dynamic topography from Rio et al. (2014). The latter is performed by averaging the outputs from the Mediterranean Forecasting 
System ocean model as a first guess, updated with in situ data from the available observations in the area. The author affirms that this dataset constitutes the best estimate of the mean surface circulation that is currently available for the WMed. Second, ROMSWMED32 eddy kinetic energy is compared with estimations derived from altimetry, drifter trajectories, and the parent simulation NEMOMED12. Although the spatial distributions show similar patterns in the four datasets, the values are quite lower for altimetry and NEMOMED12. By contrast, energy values obtained from ROMSWMED32 are closer to those derived from drifters, as expected from the higher resolution of this model. Finally, validation of the thermohaline content is performed by comparing ROMSWMED32 with the NEMOMED12 model and with the gridded Enhanced Ocean Data Assimilation and Climate Prediction (ENACT)-ENSEMBLES version 4 (EN4) product from observational data. Time series of volume-averaged temperature and salinity at different layers show that both models slightly overestimate the heat and salt contents, especially in the intermediate (150-600 m) and deep (600-3000 m) layers. ROMSWMED32 also displays a significant positive trend over time in both variables within the deep layer. This could be due to slight differences in the transports through the boundaries, mainly the eastern one, computed from ROMS and NEMO. The author states that the trend in the saline content could be partly responsible for the inability of ROMSWMED32 to properly reproduce deep convection in the Gulf of Lions, while the parent NEMOMED12 simulation does. Exploring the sources of such deviations is not our goal, although we must take this constraint into consideration for the computation and interpretation of energy budgets, with special care to potential energy. A precise model description and validation can be found in Escudier (2015) and Escudier et al. (2016).

The model domain covers the western Mediterranean Basin between $7.4^{\circ} \mathrm{W}-10^{\circ} \mathrm{E}$ and $34.6^{\circ}-44.7^{\circ} \mathrm{N}$, spanning from the Gulf of Cadiz to Corsica and Sardinia with a grid resolution of $1 / 32^{\circ}$ (about $3.5 \mathrm{~km}$ ). The simulation spans from 1992 to 2012, although our analysis starts in 1995. Energy analysis requires the quantities involved in the budget to be statistically stationary; such stationarity is assessed in terms of the stability of the time series of the domain-integrated amounts, proving that a 3-yr spinup period is needed for the model variables to reach equilibrium (see appendix B for further details). Once achieved, nearly two decades of daily outputs enable reliable statistics for the prognostic variables and, together with the adequate spatial resolution, ensure an appropriate characterization of the mesoscale dynamics of the area.

\section{b. Energy analysis}

Energy analysis is based on the concepts of mean and eddy flows kinetic and potential energy budgets. In this work, mean flow is defined as the local time average over the 18 -yr period, while the term eddy refers to the deviation from the long-term mean. This definition of eddy includes many sources of variability within a wide spectrum of scales, from the small-scale fluctuations emerging from local dynamics to the long-term tendencies arising from the nonstationary atmospheric and boundary forcings. However, this formulation is statistically consistent for the derivation of the energy balance equations and suitable for the study of the eddy-mean flow interaction.

The terms and formulations required to perform our energy analysis are summarized below. First, simplified formulations for the mean kinetic energy (MKE) and eddy kinetic energy (EKE), and for the mean available potential energy (MAPE) and eddy available potential energy (EAPE) are introduced. Then, the Lorenz energy cycle is presented and its application to ocean dynamics is considered and discussed. Derivation of the energy balance equations involved in the LEC formulation is summarized, and the terms responsible for EKE production are identified for further analysis.

\section{1) Kinetic energy And available POTENTIAL ENERGY}

According to the theory of random processes for turbulent flows, we assume the flow to be statistically stationary (Pope 2000). In this regard, after the model has been initialized, the flow field passes through a transient spinup period until it reaches a statistically stationary state. This means that while the prognostic variables vary in time, their statistics (mean and variance) are time independent. Under such assumptions, the components of the flow field $\mathbf{u}(t)$ can be written as the sum of their temporal mean $\overline{\mathbf{u}}$ and a time-varying fluctuation $\mathbf{u}^{\prime}(t)$. If we denote the zonal, meridional, and vertical velocity components at a given time as $u, v$, and $w$, respectively, we can write

$$
u=\bar{u}+u^{\prime}, \quad v=\bar{v}+v^{\prime}, \quad w=\bar{w}+w^{\prime},
$$

where overbars represent the time mean over the 18 years of simulation and primes denote the time-dependent fluctuating part (the eddy component of the flow). From the previous formulation, the time-averaged $\mathrm{KE}$ of the flow at a given location can be decomposed into the sum of an MKE and a time-averaged EKE. These terms, per unit volume, are defined as

$$
K_{m}=\frac{1}{2} \rho_{0}\left(\bar{u}^{2}+\bar{v}^{2}\right), \quad \text { and }
$$




$$
K_{e}=\frac{1}{2} \rho_{0} \overline{\left(u^{\prime 2}+v^{\prime 2}\right)} .
$$

The contribution of the vertical component of the velocity field $w$ is not considered here, as it is one or two orders of magnitude lower than the horizontal components. The total KE can be readily obtained from Eqs. (2)-(4) as

$$
K=\frac{1}{2} \rho_{0}\left[\bar{u}^{2}+\bar{v}^{2}+\overline{\left(u^{\prime 2}+v^{\prime 2}\right)}+2 \overline{\bar{u} u^{\prime}}+2 \overline{\bar{v} v^{\prime}}\right]=K_{m}+K_{e},
$$

since $\overline{\bar{u} u^{\prime}}=\overline{\bar{v} v^{\prime}}=0$ by definition. The reader is referred to appendix $\mathrm{C}$ for further details on EKE derivation from the Reynolds-averaged Navier-Stokes equations.

On the other hand, the available potential energy (APE) of a fluid at a given state represents the amount of potential energy that can be converted into KE during an adiabatic rearrangement of the fluid. In a broad sense, it can be defined as the difference between the PE for a given state of the fluid and a hydrostatic, stable reference state in which isentropic surfaces are horizontal and thus the PE is minimal (Reid et al. 1981). Quoting this work, although the elastic internal energy also supplies PE to the fluid, the APE of the ocean is dominated by the gravitational PE. Given the complexity of the calculation of the internal energy, our analysis is restricted to the gravitational contribution to APE, for which we adopt a commonly used definition for the ocean based on the quasigeostrophic approximation (Huang 2005; von Storch et al. 2012; Chen et al. 2014). As in the case of KE, the APE per unit volume at a given location can be divided into a time MAPE $P_{m}$ and an EAPE $P_{e}$ :

$$
\begin{aligned}
& P_{m}=-\frac{g}{2 n_{0}} \overline{\rho^{*^{2}}}, \quad \text { and } \\
& P_{e}=-\frac{g}{2 n_{0}} \overline{\rho^{* / 2}},
\end{aligned}
$$

where $n_{0}$ is the vertical gradient of the local potential density averaged in time and over the study area (assumed constant at each vertical level). The density anomaly $\rho^{*}=\rho-\rho_{r}$ is the deviation of the local density from that of a predefined reference state $\rho_{r}$ chosen to be the area-averaged time-mean density, thus constant at each level. While the APE of the mean flow (MAPE) is determined by the time mean of the density anomalies $\overline{\rho^{*}}$, the available potential energy of the eddy flow (EAPE) is given by its variance, since $\overline{\rho^{* / 2}}=\overline{\left(\rho^{*}-\overline{\rho^{*}}\right)^{2}}$.

Equations (3) and (4) and (6) and (7) are used in the next section to obtain the energy equations involved in the LEC. The definitions of $P_{m}$ and $P_{e}$ are strongly affected by the choice of the reference density and, further, several assumptions regarding the equation of state have to be adopted in order to obtain their respective energy equations. Although this constrains the interpretation of the APE in a quantitative sense, these approximations provide manageable expressions for their derivation and are suitable for analysis of the mean-eddy flow energy transfers involving the LEC (von Storch et al. 2012).

\section{2) THE LEC}

Lorenz (1955) developed a formulation for the energy cycle in the atmosphere based on considering the fluid as a heat engine: "the incoming solar radiation generates potential energy that is transferred to kinetic energy and is finally lost to frictional dissipation" (Li et al. 2007, p. 1). In particular, the LEC describes the steady-state balance of four energy reservoirs: the MKE and the MAPE, $K_{m}$ and $P_{m}$, respectively; and the time-averaged EKE and EAPE from the time-varying circulation, $K_{e}$ and $P_{e}$, respectively.

von Storch et al. (2012) provide an estimation of the LEC for the World Ocean derived from numerical simulation. This study, however, warns about the application of the LEC to ocean dynamics for different reasons: from the initial hypothesis (the ocean cannot be considered as a heat engine, since the energy is mainly driven by air-sea interactions) to the fact that determining the amount of APE to be converted into KE is a complex issue in weakly stratified regions with complex topography (Wu et al. 2017). However, the LEC is a valuable tool for studying the energy balance and the transfer between the different energy forms (Marchesiello et al. 2003; Sorgente et al. 2011; Renault et al. 2016). The major constraint is the selection of appropriate analysis regions since, as stated by Harrison and Robinson (1978): because the terms of the LEC imply volume integration of the energy terms, it is desirable that the analysis regions be a quasi-homogeneous part of the flow, kinematically and dynamically distinct from the surroundings.

Complete derivations of the four energy balance equations involved in the LEC can be found in von Storch et al. (2012) (see also appendix D). Because our study region is a semienclosed domain, we adopt a simplified notation for the governing equations derived in Chen et al. (2014) as far as they permit to identify whether eddy-mean flow interactions are local or nonlocal, as will be explained below.

The four energy components satisfy the balance equations:

$$
\begin{aligned}
& \frac{\partial K_{m}}{\partial t}+\nabla \cdot\left(\overline{\mathbf{u}} K_{m}\right)+\nabla \cdot(\overline{\mathbf{u}} \bar{p}) \\
& \quad=-D\left(K_{m}\right)+M\left(K_{m}\right)+X\left(K_{m}\right),
\end{aligned}
$$




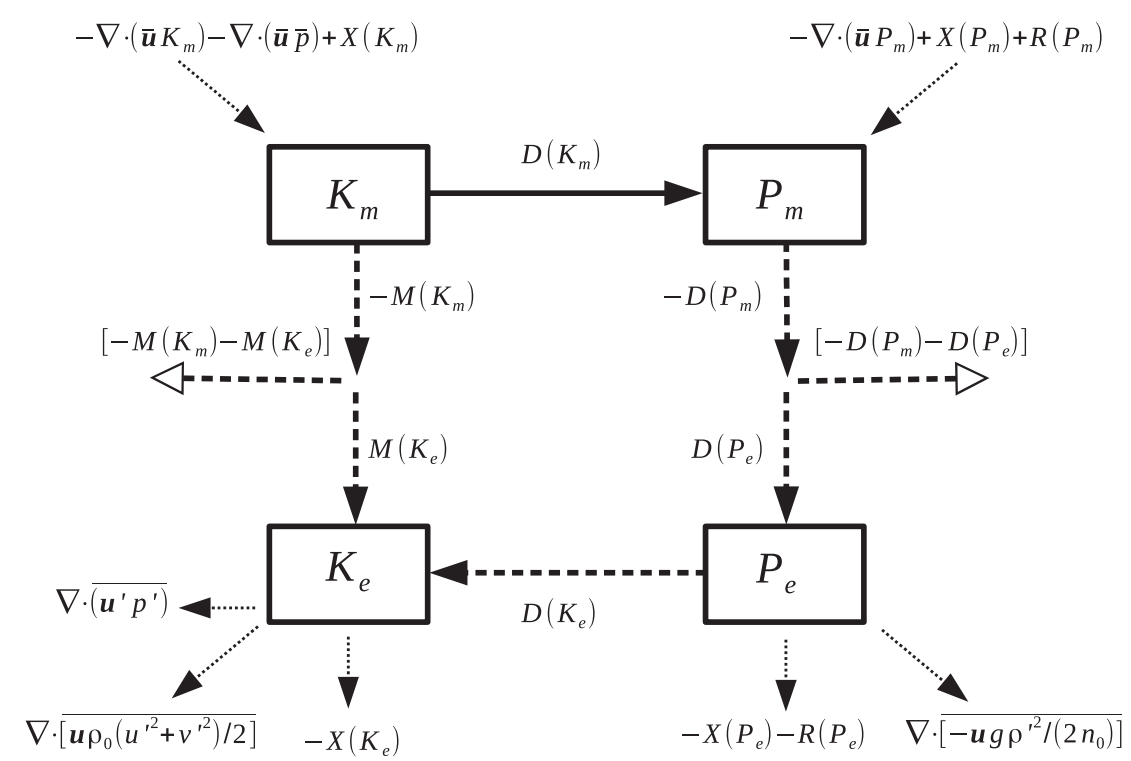

FIG. 3. Oceanic LEC showing the transfers among the four energy reservoirs. The amounts correspond to the same terms in Eqs. (8)-(11) integrated over the considered ocean volume. Dashed arrows depict the possible routes for eddy-mean flow interaction through eddy momentum fluxes $M$ and through eddy density fluxes $D$. When mean-eddy flow interactions are local, the terms in brackets are negligible, and all the energy released from the mean flow is transferred to the local eddies. The other terms involved in the energy budget equations but not considered in this analysis are represented by dotted arrows. Adapted from Chen et al. (2014).

$$
\begin{aligned}
\frac{\partial K_{e}}{\partial t}+\nabla \cdot \overline{\left[\mathbf{u} \rho_{0}\left(u^{\prime 2}+v^{\prime 2}\right) / 2\right]}+\nabla \cdot \overline{\left(\mathbf{u}^{\prime} p^{\prime}\right)} & \\
=D\left(K_{e}\right)+M\left(K_{e}\right)+X\left(K_{e}\right), & \\
\frac{\partial P_{m}}{\partial t}+\nabla \cdot\left(\overline{\mathbf{u}} P_{m}\right)= & D\left(P_{m}\right)+D\left(K_{m}\right) \\
& +X\left(P_{m}\right)+R\left(P_{m}\right), \text { and }
\end{aligned}
$$

$$
\begin{aligned}
\frac{\partial P_{e}}{\partial t}+\nabla \cdot \overline{\left[-\mathbf{u} g \rho^{2} /\left(2 n_{0}\right)\right]}= & D\left(P_{e}\right)-D\left(K_{e}\right) \\
& +X\left(P_{e}\right)+R\left(P_{e}\right),
\end{aligned}
$$

where $D(\cdot)$ and $M(\cdot)$ denote the rate of change of the energy form given in parentheses resulting from eddy density fluxes and eddy momentum fluxes, respectively; $X\left(P_{m}\right)$ and $X\left(P_{e}\right)$ involve rates of change related to vertical mixing, heat, and freshwater fluxes; and $X\left(K_{m}\right)$ and $X\left(K_{e}\right)$ are related to wind stress, friction, and bottom drag. The $R(\cdot)$ terms represent higher-order quantities that can be neglected in the adopted quasigeostrophic framework. The terms on the lhs in Eqs. (8)-(11) represent the corresponding energy rates of change resulting from temporal variations, advection, and pressure work, respectively. Neglecting the temporal rates of change, since we are considering a statistically steady state, the oceanic LEC is summarized in Fig. 3.
With the aim to investigate the possible physical mechanisms behind perturbation growth and their spatial distribution along the WMed domain, this study is focused on the mean-eddy flow interaction terms that involve EKE production. More specifically,

$$
D\left(P_{m}\right)=\frac{g}{n_{0}} \overline{\rho^{*}} \nabla_{H} \cdot\left(\overline{\mathbf{u}_{H}^{\prime} \rho^{\prime}}\right),
$$

represents the energy released from the unstable mean flow resulting from horizontal density fluxes. The corresponding eddy energy gain is

$$
D\left(P_{e}\right)=\frac{g}{n_{0}} \overline{\rho^{\prime} \mathbf{u}_{H}^{\prime}} \cdot \nabla_{H} \overline{\rho^{*}},
$$

from which eddy growth implies that both the horizontal eddy density flux and the mean horizontal density gradient point in the same direction.

Conversion from EAPE to EKE is driven by eddy buoyancy work and is defined as

$$
D\left(K_{e}\right)=-g \overline{\rho^{\prime} w^{\prime}} .
$$

The sinking of denser water masses and the upwelling of lighter ones involves a reduction of the PE of the system offset by an increase of $\mathrm{KE}$, resulting in positive 
values of $D\left(K_{e}\right)$. This is also referred to as the baroclinic conversion term.

The rate of change of MKE caused by eddy momentum fluxes is defined as

$$
M\left(K_{m}\right)=-\rho_{0}\left[\bar{u} \nabla \cdot\left(\overline{u^{\prime} \mathbf{u}^{\prime}}\right)+\bar{v} \nabla \cdot\left(\overline{\left(v^{\prime} \mathbf{u}^{\prime}\right.}\right)\right],
$$

while the gain in EKE results from interaction of the horizontal Reynolds stress field with the mean flow shear is defined as

$$
M\left(K_{e}\right)=-\rho_{0}\left(\overline{u^{\prime} \mathbf{u}^{\prime}} \cdot \nabla \bar{u}+\overline{v^{\prime} \mathbf{u}^{\prime}} \cdot \nabla \bar{v}\right) .
$$

From the pairs of Eqs. (12) and (13) and Eqs. (15) and (16), a local eddy-mean flow interaction implies that all the energy released from the mean flow is transferred to the eddy flow in the same region. In this case, the quantities $-D\left(P_{m}\right)$ and $-M\left(K_{m}\right)$ amount exactly to $D\left(P_{e}\right)$ and $M\left(K_{e}\right)$, respectively, when integrated over the region volume. On the other hand, the interaction is considered nonlocal when part of the energy released from the mean flow is conveyed to other regions. Following the formulation derived in Chen et al. (2014), the eddy-mean flow interaction is of a local nature if the volume integrals of the divergence forms

$$
\begin{aligned}
& \int_{V}\left[D\left(P_{m}\right)+D\left(P_{e}\right)\right] d V \\
& =\int_{V} \nabla_{H} \cdot\left(\overline{\overline{\mathbf{u}_{H}^{\prime}} \rho^{\prime}} \frac{g}{n_{0}} \overline{\rho^{*}}\right) d V, \text { and } \\
& \int_{V}\left[M\left(K_{m}\right)+M\left(K_{e}\right)\right] d V \\
& =-\rho_{0} \int_{V}\left[\nabla \cdot\left(\overline{\bar{u} u^{\prime} \mathbf{u}^{\prime}}\right)+\nabla \cdot\left(\overline{\bar{v} v^{\prime} \mathbf{u}^{\prime}}\right)\right] d V
\end{aligned}
$$

are negligible (see Fig. 3).

From Eqs. (8)-(11) and the simplified LEC schematized in Fig. 3, a regional characterization of the sources of eddy-mean flow interactions can be depicted by checking the local predominance of any of these terms among the others, as will be described in section $3 \mathrm{~d}$. In fact, baroclinic instabilities set the conditions for MAPE conversion into EKE through the pathway $-D\left(P_{m}\right) \rightarrow D\left(P_{e}\right) \rightarrow D\left(K_{e}\right)$, while barotropic instabilities, reflecting the interaction of the mean flow with horizontal Reynolds stresses, result in a KE exchange from the mean to the eddy flow via $-M\left(K_{m}\right) \rightarrow M\left(K_{e}\right)$.

Besides the mean-eddy flow energy routes, the role of the mean and time-varying winds in the generation of MKE and EKE [considered in terms $X\left(K_{m}\right)$ and $X\left(K_{e}\right)$ in Eqs. (8) and (9), respectively] is also analyzed, given the known strong influence of surface winds in driving ocean dynamics in key areas of the domain, such as the Gulf of Lions and Alboran Sea. At a given location, KE inputs from the mean and time-varying winds to the mean and eddy flows, respectively, are defined as

$$
\begin{aligned}
f_{m} k_{m} & =\overline{\tau_{x, s}} \bar{u}+\overline{\tau_{y, s}} \bar{v}, \quad \text { and } \\
f_{e} k_{e} & =\overline{\tau_{x, s}^{\prime} u}+\overline{\tau_{y, s}^{\prime} v},
\end{aligned}
$$

where $\overline{\tau_{x, s}}$ and $\overline{\tau_{y, s}}$ represent the zonal and meridional components of the time-averaged surface wind stress, respectively, and $\tau_{x, s}^{\prime}$ and $\tau_{y, s}^{\prime}$ their corresponding fluctuations. The global contribution of surface winds to the MKE and EKE budgets can be obtained by integrating the aforementioned quantities over the domain area.

Energy transfer from the mean surface winds to the mean flow $\left(f_{m} k_{m}\right)$ can also indirectly result in EKE production, following a conversion path that involves, first, a transformation from $K_{m}$ into $P_{m}$ through buoyancy flux, represented by the $D\left(K_{m}\right)$ term in Eqs. (8) and (10) and defined as

$$
D\left(K_{m}\right)=-g \overline{\rho^{*}} \bar{w},
$$

followed by the conversion route $P_{m} \rightarrow P_{e} \rightarrow K_{e}$ driven by baroclinic instabilities (Marchesiello et al. 2003).

\section{Results}

To further characterize the mesoscale dynamics of the western Mediterranean region, we carry out a statistical analysis of KE budgets and their spatial variability. As a start, the mean circulation patterns derived from the model are analyzed and linked to the KE budgets for the mean and time-varying flows.

\section{a. Surface mean currents}

Permanent large-scale currents in the WMed region are well reproduced in the simulation, averaged over the whole 18-yr period (Fig. 4). Incoming Atlantic water (AW) through the Strait of Gibraltar first follows the permanent Western Anticyclonic Gyre (WAG) followed by the weaker and quasi-permanent Eastern Anticyclonic Gyre (EAG) south of the Gulf of Almeria. Seasonal analysis (not shown) reveals that both structures appear more intense and well defined in spring and summer, with mean speeds reaching more than $90 \mathrm{~cm} \mathrm{~s}^{-1}$, while the strength of the currents decay during autumn and winter. The EAG shows higher variability in both size and position which, in turn, modulates the size and strength of the Almeria-Oran Front (AO), where the first major clash between incoming fresh AW and Mediterranean 


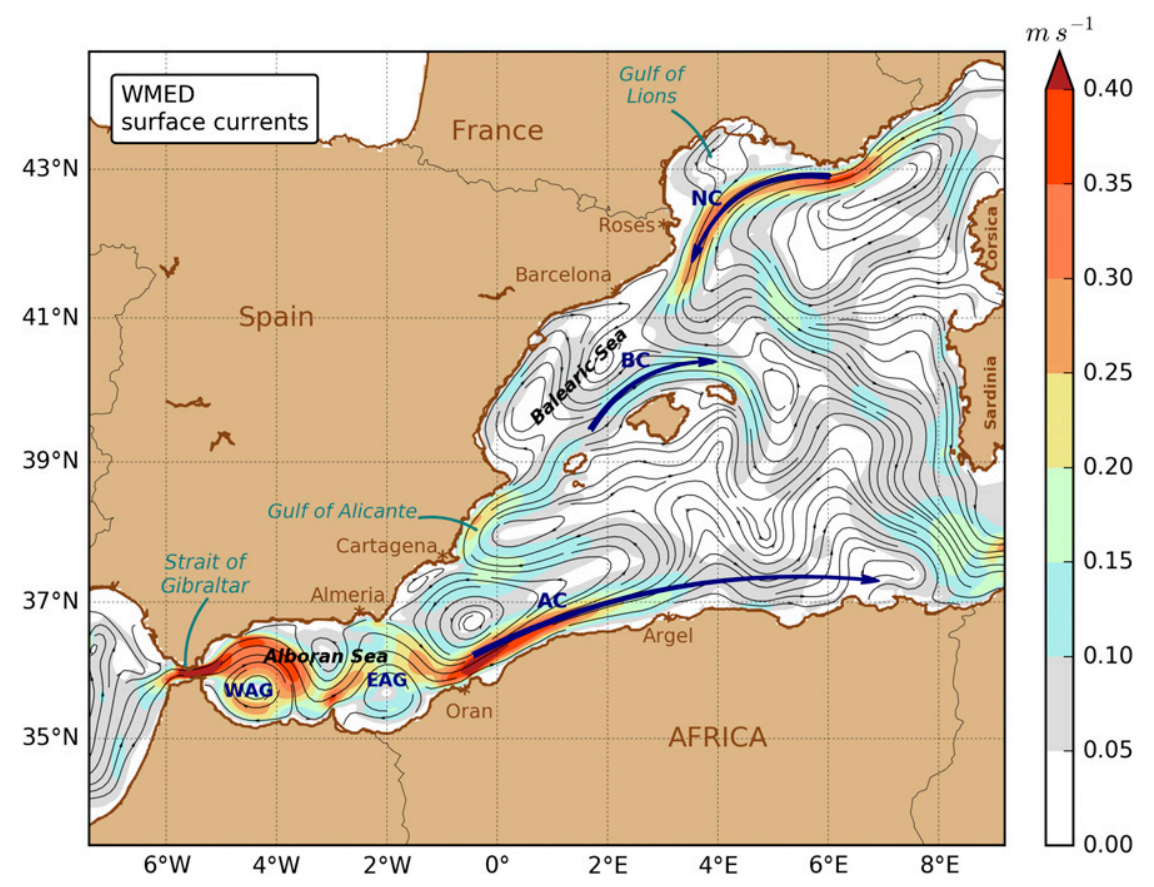

FIG. 4. Averaged surface velocity for the 1995-2012 period from the model output. Streamlines are depicted in black, whereas dark blue arrows show the main paths of the principal currents: Northern Current (NC), Balearic Current (BC), and Algerian Current (AC). Although the color bar range for surface speeds is restricted to $0.40 \mathrm{~m} \mathrm{~s}^{-1}$, maximum values up to $0.90 \mathrm{~m} \mathrm{~s}^{-1}$ are registered through the Strait of Gibraltar and around $0.5^{\circ} \mathrm{W}$ within the AC.

water (MW) occurs. From this point, most of the flow continues along the African coast, forming the Algerian Current (AC). It is especially strong and narrow between $1^{\circ} \mathrm{W}$ and $1^{\circ} \mathrm{E}$, but then it starts meandering and generating short-lived mesoscale eddies that detach northward from the main current, spreading AW into the interior of the basin. This behavior is more pronounced during the warmer seasons, while in autumn and winter the AC flows eastward, mostly concentrated along the coast. The spreading of this current can be first detected around $2^{\circ} \mathrm{E}$, where it draws a cyclonic deflection toward the Gulf of Alicante. When facing the coast, this branch forms an anticyclonic gyre with significant intensity on its northern flank. The intensity and variability of this northward current in the Gulf of Alicante strongly affects the water transport through the Ibiza Channel and, by extension, the circulation patterns within the Balearic Sea, a semienclosed subbasin embedded between the Catalonian coast and the Balearic archipelago. Two principal inputs feed this area: across its northern edge the well-defined Northern Current (NC) advects cooler MW, while in the south the narrow Ibiza Channel receives warmer waters from the Gulf of Alicante. The main permanent structure is the Balearic Current (BC), which flows northeastward from the Ibiza Channel along the northern edges of the three main islands. Initially fed by the southern warm waters, it is reinforced along its trajectory by occasional currents derived from interior meanders and small eddies and eventually by incoming waters crossing the Mallorca Channel. At the northern edge, a significant contribution from colder waters apparently detached from the original $\mathrm{NC}$ helps to enhance the $\mathrm{BC}$ in the last part of its journey toward Menorca. A strong signature of the NC is seen in the area of the Gulf of Lions, with a noticeable weakening in summer. North of the Balearic Islands, this current undergoes a marked deflection and divides into two main branches: the first branch starts to detach southeastward along the gulf path, merging with the BC north of Menorca. Part of this flow completes a cyclonic gyre covering the northern half of the basin, while the rest keeps flowing southeastward and joins the remnants of the Algerian Current toward the Tyrrhenian Sea. The second branch of the NC keeps flows along the continental shelf, entering the Balearic Sea. Given the complex topographic configuration of this area, the weakened residual branch of the $\mathrm{NC}$ can occasionally keep flowing southward along the Spanish coast, crossing the Ibiza Channel or, mostly, undergo a major cyclonic deflection around $40^{\circ} \mathrm{N}$ and join the $\mathrm{BC}$ in front 
of Mallorca coast, as depicted from the time-averaged pattern in Fig. 4.

\section{b. Kinetic energy analysis}

Mesoscale features derived from the simulation are analyzed on the basis of KE budgets and their spatial variability. Following the definitions given in Eqs. (3) and (4), maps of surface MKE and time-averaged EKE for the period 1995-2012 in the WMed are shown in Fig. 5.

Spatial distributions of both MKE and EKE present significant differences. The highest MKE is concentrated along the paths of the main currents: the Alboran system, AC, NC, and, with less intensity, along the BC and the Cartagena Current. By contrast, the EKE distribution presents a very disperse pattern, with a strong signal throughout the Alboran region (reaching nearly $1300 \mathrm{~cm}^{2} \mathrm{~s}^{-2}$ ) and along and offshore of the AC. Notable but less intense is the signal along the $\mathrm{BC}$, while the track of the NC is barely noticeable. The scattered distribution of EKE reveals high variability in the position and intensity of these structures over time; in this regard, the $\mathrm{AC}$ is known to display a narrow and well-defined pathway at the beginning, also depicted in the MKE map, while showing increasing instabilities as it advances eastward, in the form of meanders and eddies that detach from the initial along-coast current toward the center of the basin, as revealed by the high values of EKE covering the southern half of the domain. The opposite situation is found along the track of the $\mathrm{NC}$, where the negligible EKE signal contrasts with the large MKE, revealing the steady position and intensity of the main stream.

\section{c. Energy budgets}

KE budgets have been calculated by integrating the corresponding time-averaged quantities for the period 1995-2012 over the entire WMed domain. While MKE amounts to 0.6 PJ, the volume-integrated EKE reaches 2.3 PJ-more than 3 times the MKE budget. Both magnitudes are mostly concentrated in the upper $100 \mathrm{~m}$ and remain virtually negligible deeper than $300 \mathrm{~m}$. In general, KE generation and conversion rates display a seasonal nature. From the area integral of the $f_{e} k_{e}$ term in Eq. (20), time-varying winds supply a total amount of $2.7 \mathrm{GW}$ of $\mathrm{KE}$ to the time-varying circulation. The spatial distribution in Fig. 6 (right) reveals a noticeable increase during winter, according to the enhancement of the wind regime during the cold season. In contrast, the mean wind work budget given by the area integral of the $f_{m} k_{m}$ term in Eq. (19) accounts for only $685 \mathrm{MW}$-around $25 \%$ of the total $f_{e} k_{e}$ contribution.

Larger inputs to the $f_{e} k_{e}$ budget come from the Alboran Sea and Gulf of Lions, the areas most affected
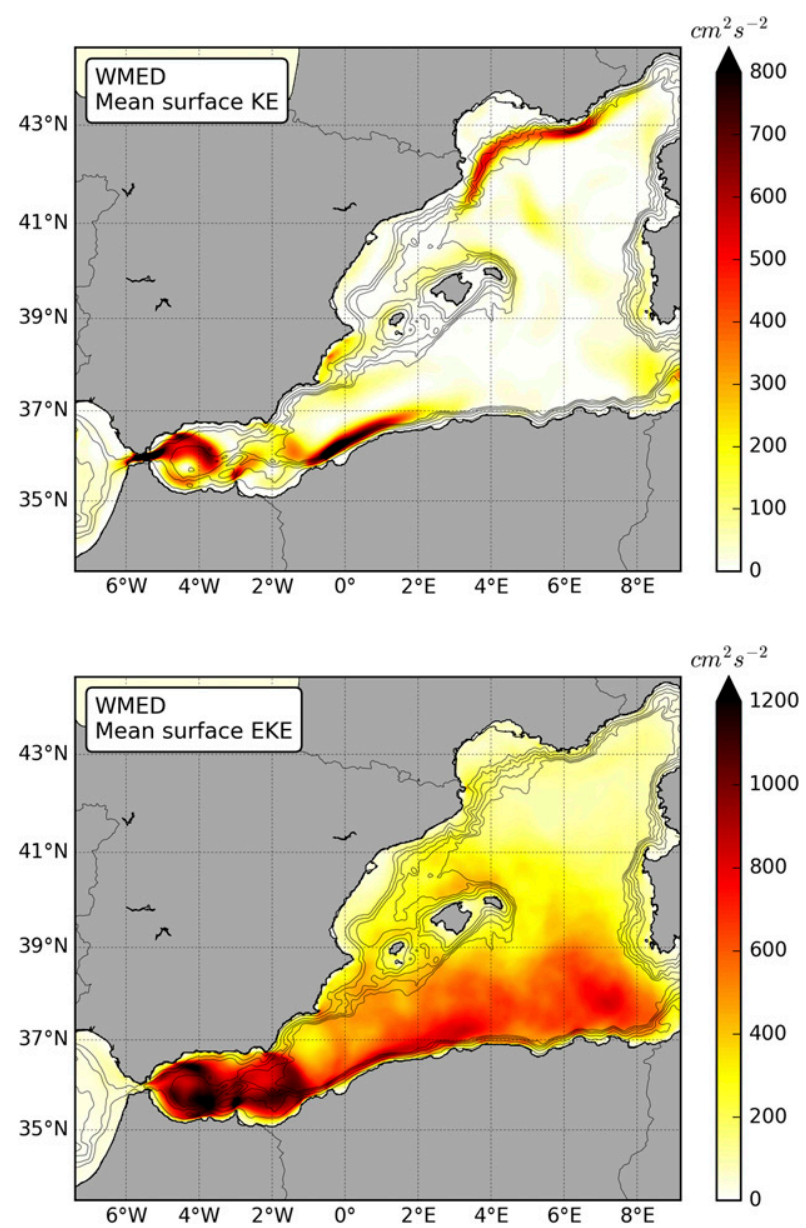

FIG. 5. (top) Surface MKE $\left(\mathrm{cm}^{2} \mathrm{~s}^{-2}\right)$ computed from mean surface velocity components, $\bar{u}$ and $\bar{v}$ for the period 1995-2012 following Eq. (3) divided by $\rho_{0}$. Values above $800 \mathrm{~cm}^{2} \mathrm{~s}^{-2}$ reach up to $3660 \mathrm{~cm}^{2} \mathrm{~s}^{-2}$ within the Gibraltar Strait and up to $1300 \mathrm{~cm}^{2} \mathrm{~s}^{-2}$ around $0.5^{\circ} \mathrm{W}$ in the AC. (bottom) Surface mean EKE $\left(\mathrm{cm}^{2} \mathrm{~s}^{-2}\right)$ computed by time-averaging daily EKE values, obtained from surface eddy velocity components, $u^{\prime}$ and $v^{\prime}$, following Eq. (4) divided by $\rho_{0}$. Within the Alboran Gyres, mean EKE values reach up to $1300 \mathrm{~cm}^{2} \mathrm{~s}^{-2}$. Both figures show 200-, 500-, 1000-, 1500-, and 2000-m isobaths (black contour lines)

by the strongest winds. In contrast, the regional $f_{m} k_{m}$ displays a more complicated pattern for which several aspects are worth highlighting: first, in the Gulf of Lions, the inverted-V shape of positive KE generation near Cape Roses reflects the deflection of the NC into two main branches, as described in section $3 \mathrm{a}$. The interaction with the southeastward branch extends to the southeastern extreme of the domain, south of Sardinia, especially in winter. On the other hand, where the NC enters the Gulf of Lions, a marked negative contribution is reflected along both seasons, meaning that in this region the main current flows against the mean winds. The positive contribution detected in winter north of 



FIG. 6. Kinetic energy generation from wind work for (left) winter and (right) summer, from Eqs. (19) and (20) and divided by $\rho_{0}$. Note that the color bar ranges are different for each season. (top) Local MKE transfer from mean surface winds to the mean flow, and (bottom) EKE generation by wind work anomalies. Both figures show 200-, 500-, 1000-, 1500-, and 2000-m isobaths (black contour lines)

Menorca is especially strong along the last stretch of the $\mathrm{BC}$, an area that is known to be specially affected by northerly winds. During this season, the AC is also propelled eastward by following mean winds. Conversely, in summer, $f_{m} k_{m}$ (Fig. 6, bottom left) displays a much more variable pattern, with dipoles of positive and negative $f_{m} k_{m}$ which, when integrated over the whole domain, explain the minor contribution of $f_{m} k_{m}$ to the domain-integrated budget.

Regarding potential energy, as explained in section $2 \mathrm{~b}$, the APE budgets for mean and eddy flows, $P_{m}$ and $P_{e}$, are quantitatively meaningless, since their formulations are based on an ideal, predefined minimum energy state of the ocean that strongly depends on the choice of the reference density $\rho_{r}$ and is highly affected by the accuracy, the resolution of the model, and the processes solved. For this reason, its application is reserved for the analysis of the mean eddy flow interactions.

\section{d. Regional LEC and mean-eddy flow interactions}

Based on the mean currents and KE regional distributions described in previous sections and schematized in Figs. 4 and 5, respectively, the WMed domain can be divided into three main subregions that are more or less dynamically distinct from each other, although continuously interacting between them as well as with the surrounding waters (Fig. 8, right panels): The Alboran Sea, interacting with the Atlantic Ocean through the Strait of Gibraltar and bounded by the Algerian Basin to the east; the Algerian Basin, also bounded by the Tyrrhenian Sea to the east and by the Balearic Islands to the north; and the northern basin, covering the 
northernmost sector of the domain. WMed mean-eddy flow interactions have also been considered separately in these subregions in order to analyze, first, the dominant energy routes in each sector (by means of regional LECs) and, second, the spatial distributions of the energy conversion terms in Eqs. (12)-(18).

Considering the whole WMed domain, the principal routes for eddy-mean flow interaction are displayed in the simplified LEC in Fig. 7. The rates of change of the terms involving EKE conversion are obtained integrating Eqs. (12)-(16) over the domain volume. The diagram shows that baroclinic instability drives most of the EKE production via $P_{m} \rightarrow P_{e} \rightarrow K_{e}$ conversion. The values of $-D\left(P_{m}\right)$ and $D\left(K_{e}\right)$ suggest that most of the MAPE released from the mean flow is converted into EKE in the same region, while the nonzero divergence term [Eq. (17)], negative in sign, reveals that a certain amount of EAPE is also injected through the boundaries into the WMed domain. By contrast, the amount of EKE gained through eddy momentum fluxes via the path $K_{m} \rightarrow K_{e}$ is less than one-fourth of the baroclinic production. In this case, the external contribution represents about $15 \%$ of the $M\left(K_{e}\right)$ input; this energy route is therefore mainly driven by barotropic instabilities of local nature.

Regional LECs corresponding to the three WMed sectors are illustrated in Fig. 8 (left), and spatial representations of the energy conversion terms enable identifying the areas where those transformations take place (Figs. 9-11).

In the Alboran Sea (Fig. 8, top), EKE production via barotropic and baroclinic instabilities are comparable, although the divergence terms reveal that nearly half of the EAPE is injected from the surroundings, while the $K_{m} \rightarrow K_{e}$ transformation results mainly from local processes. A certain amount of $K_{m}$ is also transported out of this area, presumably toward the Algerian Basin, as expected from the dynamics in this region. From Fig. 9, the Alboran Sea displays the strongest $D\left(P_{e}\right)$ signature, showing a marked and alternating dipole pattern of positive and negative values. Red (blue) areas reveal that the eddy flow gains (releases) APE from (to) the mean flow. This is consistent with the $D\left(P_{m}\right)$ mapping, which displays a similar distribution with opposite sign although much lower amounts. These differences, as already revealed by the LEC scheme, arise from the nonlocality of the EAPE production, represented by the divergence term $\left[-D\left(P_{m}\right)-D\left(P_{e}\right)\right]$ in Fig. 11. The amounts are more significant in this area, and the red and blue patterns indicate whether the energy is leaving or entering the site. Conversion between MKE and EKE in the Alboran Sea is dominated by horizontal shear instabilities; in those areas where the flow interacts
Western Mediterranean

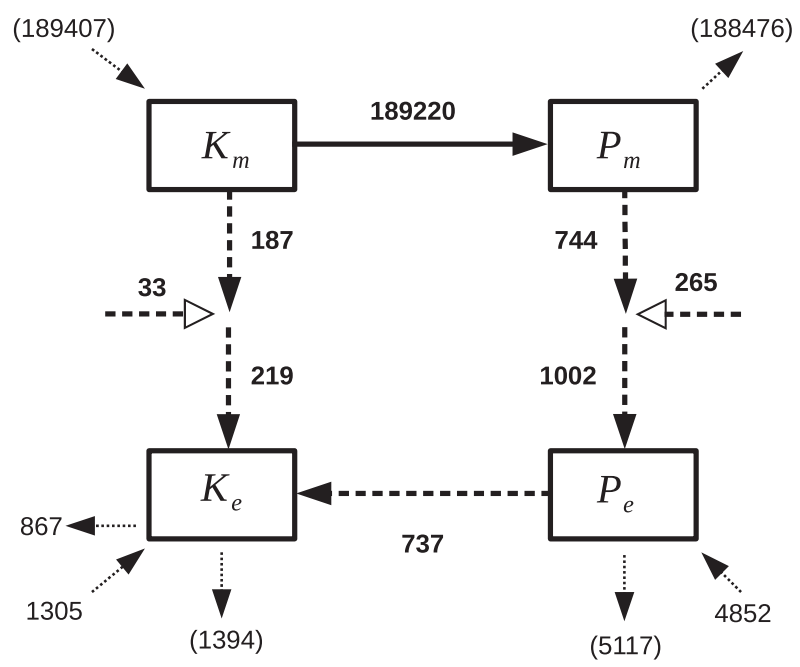

FIG. 7. LEC scheme (MW) for the WMed region following Fig. 3 and Eqs. (8)-(11). The time rates of change of the energy components are neglected, since we are considering a statistically stationary state. Amounts have been computed from time-averaged model data along the 1995-2012 period and integrating over the domain volume. The terms in parentheses are obtained from residuals. Adapted from Chen et al. (2014).

with topographic features, the barotropic conversion term displays a strong double signal: conversion is from EKE to MKE on the upstream side of the obstacle, where intensified horizontal shear inhibits perturbation growth; on the downstream side, the current becomes unstable and perturbations extract KE from the mean flow. The nonlocality of such transformations represented in Fig. 11 displays a mixed pattern, although the integrated amounts showed in the LEC reveal a net outward transport of MKE.

In the Algerian Basin (Fig. 8, middle), the nonlocality of the barotropic conversion route is much more evident. The divergence terms reveal that half of the EKE generation through eddy momentum fluxes is injected from other regions, while a small amount of the APE released from the mean flow is transported outside. The largest rates of EKE production derive from EAPE transformation. The spatial distributions of $D\left(P_{m}\right)$ and $D\left(K_{e}\right)$ shown in Fig. 9 reveal such baroclinic conversion, displaying similar patterns of inverse sign.

The nonlocality of the APE transformations is particularly apparent in the northern basin (Fig. 8, bottom), since a considerable amount of $P_{e}$ converted into $K_{e}$ is supplied from adjacent regions. Barotropic instabilities are mostly local and the related EKE production via $K_{m} \rightarrow K_{e}$ results in less than $10 \%$ of the $P_{e} \rightarrow K_{e}$ contribution.

An overview of the regional patterns of EKE production reveals that barotropic and baroclinic instabilities 


\section{Alboran Sea}
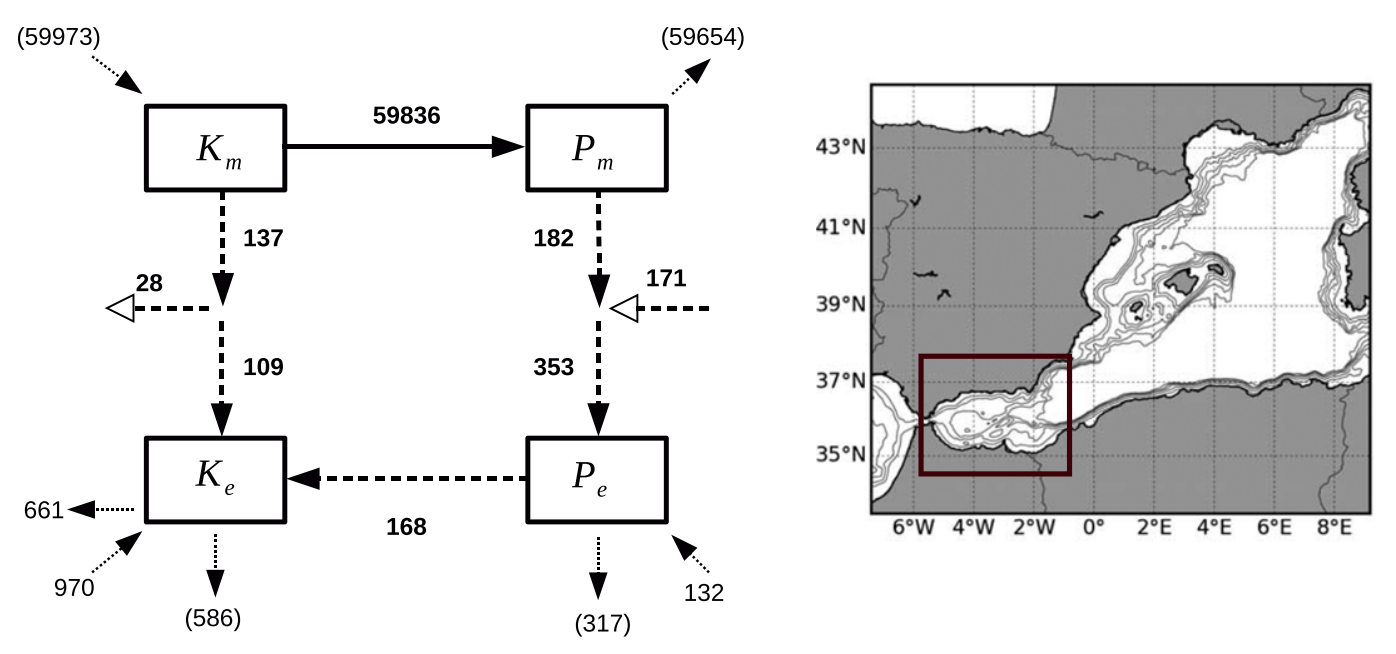

Algerian Basin
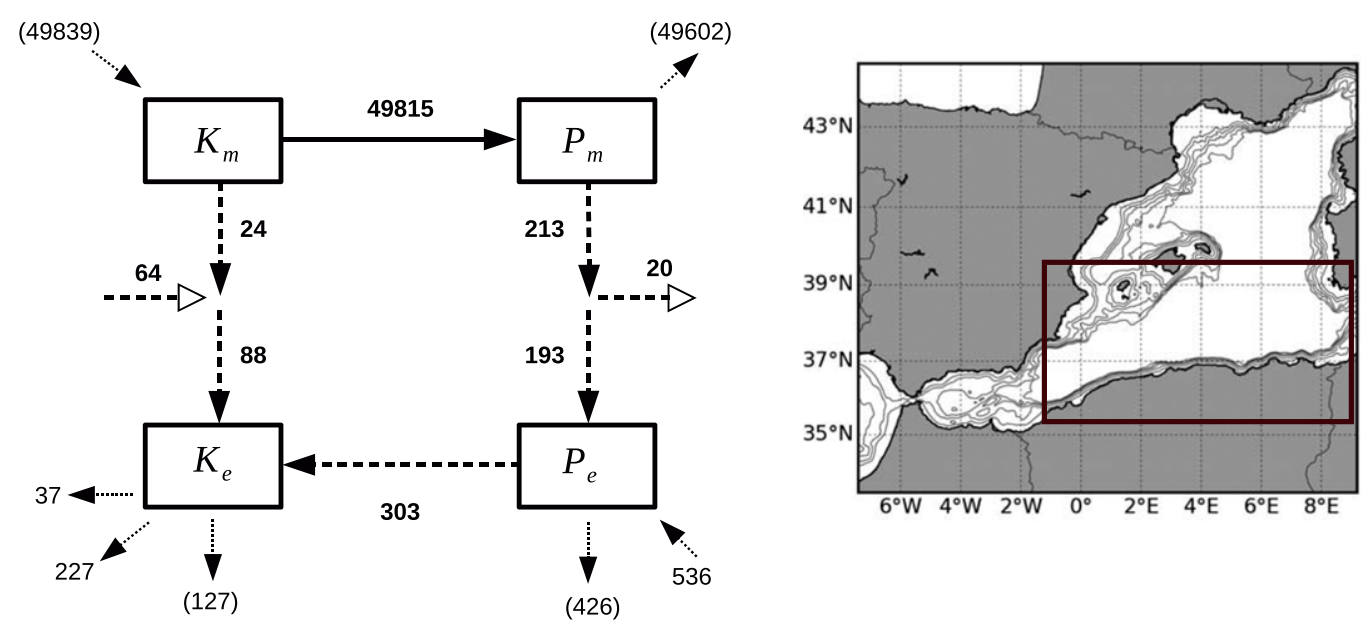

Northern Basin
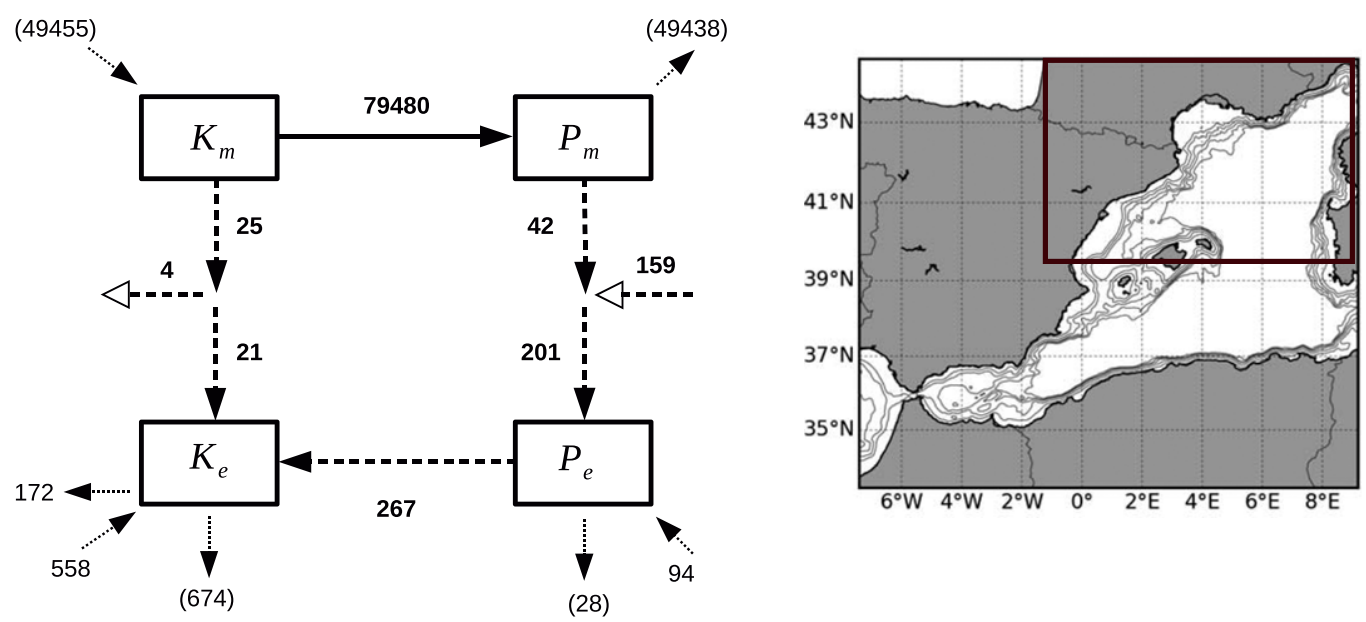

FIG. 8. (left) LEC schemes (MW) for (right) the three sectors in the WMed region following Fig. 3 and Eqs. (8)-(11), as in Fig. 7. 

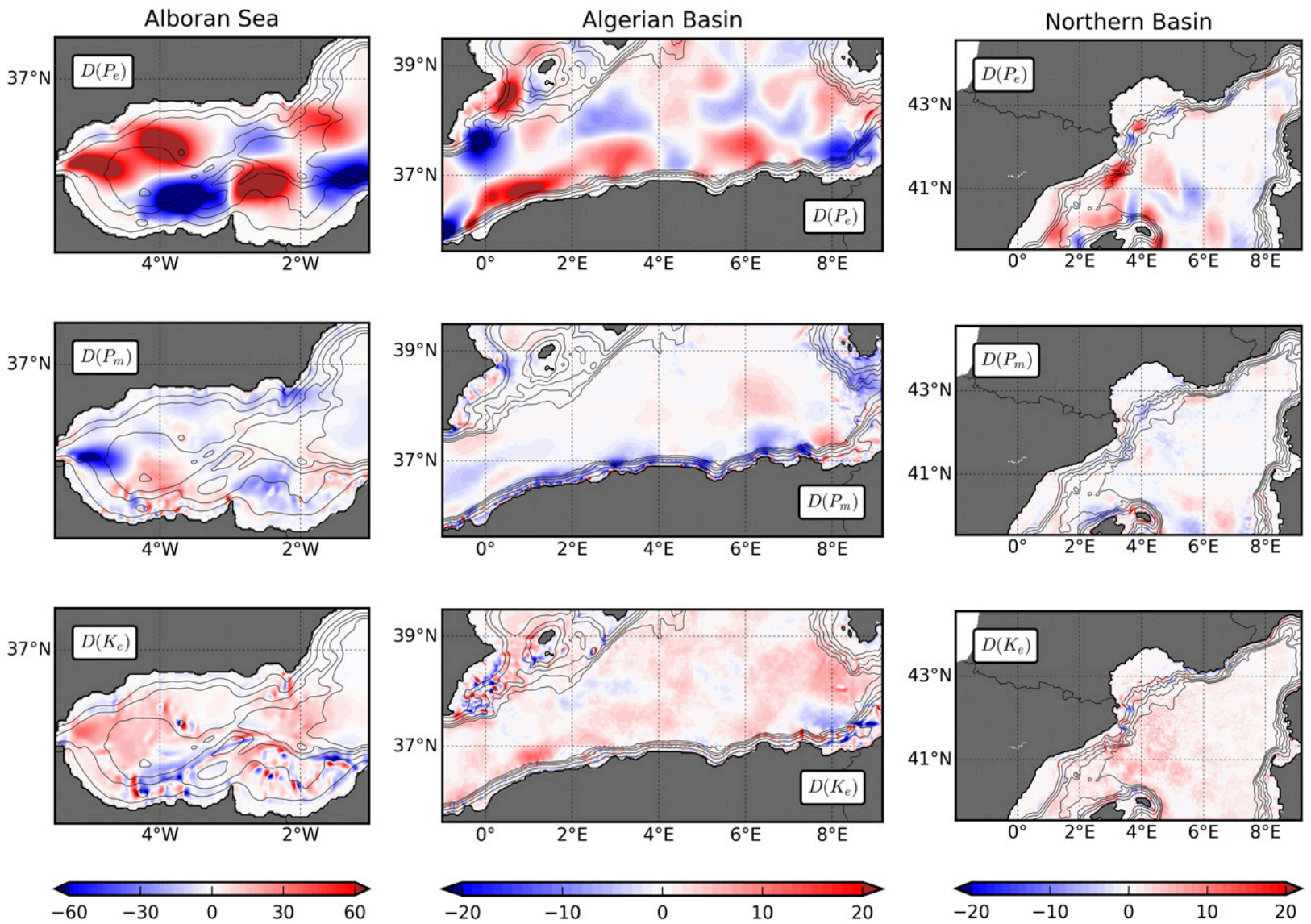

FIG. 9. Regional distributions for the (left) Alboran Sea, (center) Algerian Basin, and (right) northern basin of the mean eddy flow interaction terms driven by eddy density fluxes (top) $D\left(P_{e}\right)$, (middle) $D\left(P_{m}\right)$, and (bottom) $D\left(K_{e}\right)$, obtained by depth-integrating Eqs. (12)-(14) and dividing by $\rho_{0}\left(\mathrm{~cm}^{3} \mathrm{~s}^{-3}\right)$. Note that the color bar limits are larger in the Alboran region. All figures show 200-, 500-, 1000-, 1500-, and 2000-m isobaths (black contour lines).

occur with more intensity along the paths of the principal currents. A sequence of positive-negative dipoles are a common feature around the areas where along-coast currents flow over sharp bathymetric profiles and impact against rough, winding topographic features. This pattern frequently appears around the Balearic Islands, in the Gulf of Alicante, south of Sardinia near the African coast, around the southern ridges of both Alboran anticyclonic gyres, or along the path of the NC when crossing the Gulf of Lions. Supported by the known local dynamical behavior, the spatial characterization of the energy routes suggests that bathymetry plays a crucial role in driving the physical processes associated with EKE production. This will be discussed in the next section.

\section{Summary and discussion}

We consider a formulation of the Lorenz energy cycle for the western Mediterranean Sea, focusing on the eddy kinetic energy component, as a tool for identifying the physical mechanisms responsible for maintaining the energy balance. Eighteen years of daily data from a model simulation at $1 / 32^{\circ}$ resolution enable considering a statistically stationary state of the ocean, a necessary condition to obtain the energy balance equations involved in the LEC.

\section{a. Mesoscale characterization}

A regional characterization of the WMed within the mesoscale range is provided by analyzing the mean surface circulation patterns and their seasonal variability. The first baroclinic Rossby radius of deformation varies between 5 and $15 \mathrm{~km}$ depending on the area and time of the year considered, increasing from north to south and from winter to summer. This broadly sets the lower limit for the horizontal scale of mesoscale structures to be around $25 \mathrm{~km}$ in wavelength.

Mean large-scale currents and their seasonal variability are well reproduced from the simulation: in the Alboran Sea, the incoming AW follows the permanent 

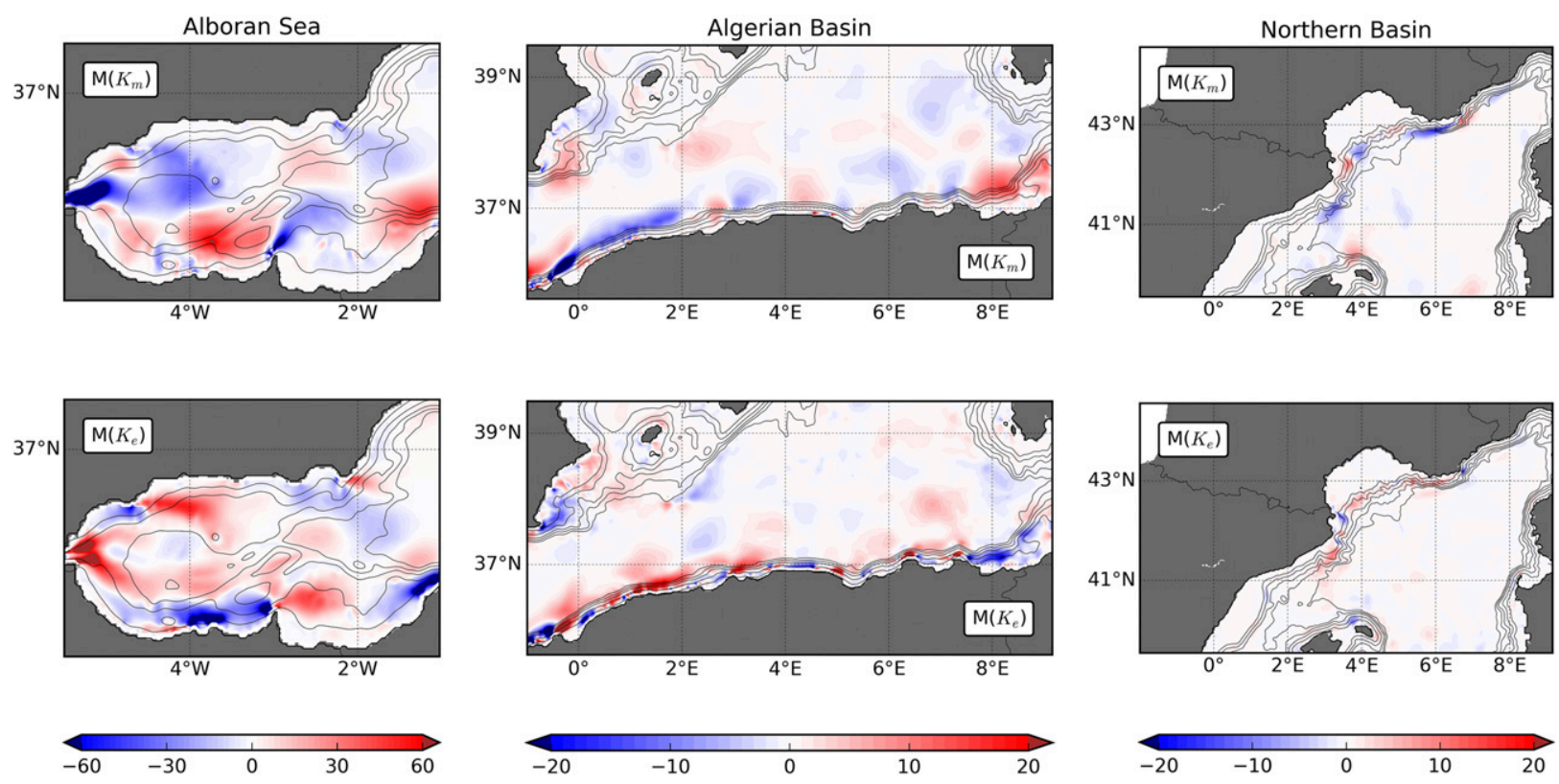

FIG. 10. Regional distributions for the (left) Alboran Sea, (center) Algerian Basin, and (right) northern basin of the mean eddy flow interaction terms driven by eddy momentum fluxes, (top) $M\left(K_{M}\right)$ and (bottom) $M\left(K_{E}\right)$, obtained by depth-integrating Eqs. (15) and (16) and dividing by $\rho_{0}\left(\mathrm{~cm}^{3} \mathrm{~s}^{-3}\right)$. Note that color bar limits are larger in the Alboran region. All figures show 200-, 500-, 1000-, 1500-, and 2000-m isobaths (black contour lines).

WAG and the quasi-permanent EAG, both being more intense and stable in summer. This can be linked to previous studies like Vargas-Yáñez et al. (2002), who show that summer months are characterized by the stability of the two-gyre system and associated fronts (i.e., the Almeria-Oran front), and Renault et al. (2012), who confirm this stable double-gyre system circulation for summer and autumn from the analysis of altimetry data.
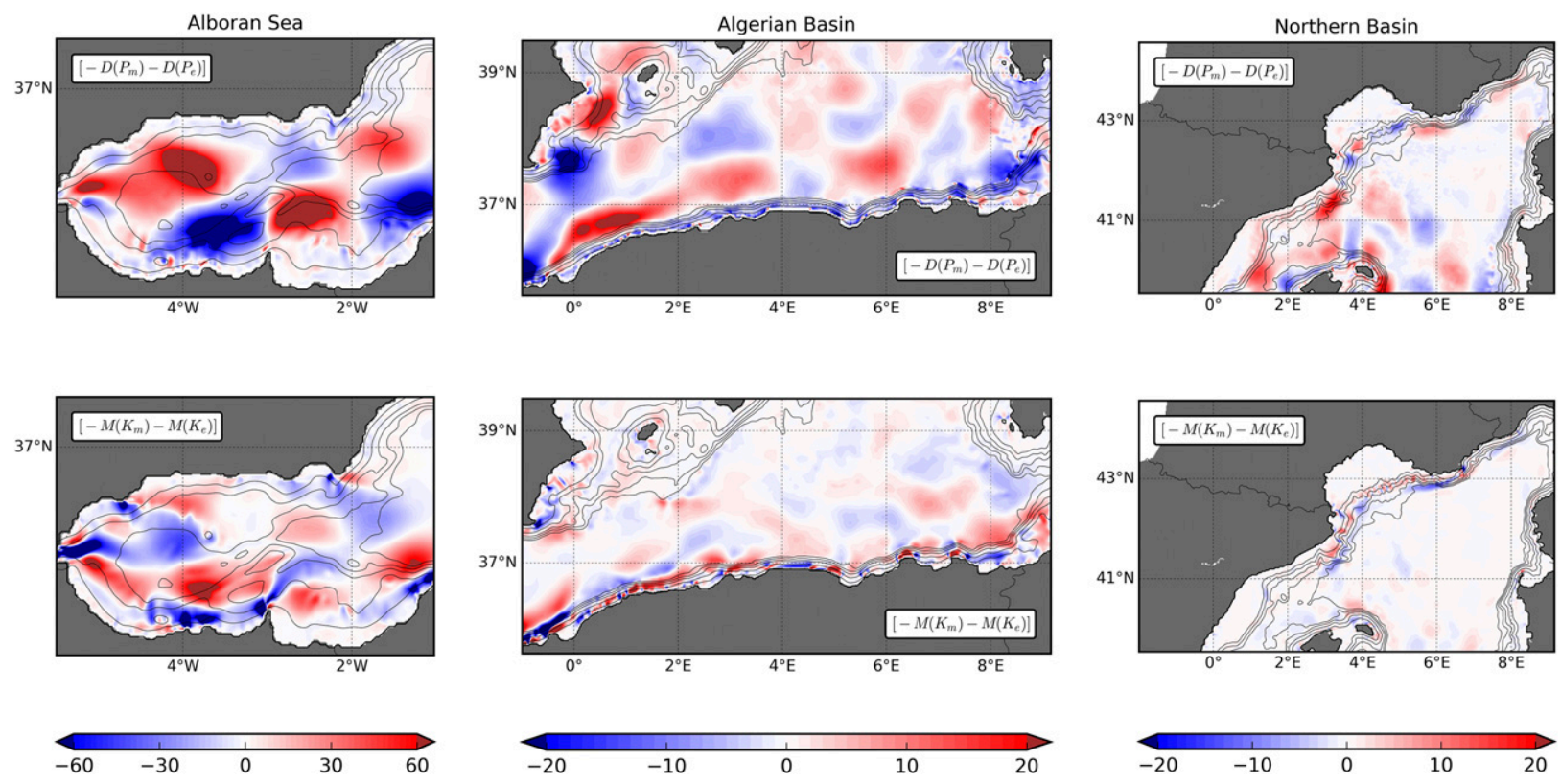

FIG. 11. Regional distributions for the (left) Alboran Sea, (center) Algerian basin, and (right) northern basin of the depth-integrated divergence terms (top) $-D\left(P_{m}\right)-D\left(P_{e}\right)$ and (bottom) $-M\left(K_{m}\right)-M\left(K_{e}\right)$ in Eqs. (17) and (18) divided by $\rho_{0}\left(\mathrm{~cm}^{3} \mathrm{~s}^{-3}\right)$. According to the corresponding LEC schemes from Fig. 8, these amounts reflect the nonlocality of mean eddy flow transformations. Note that the color bar limits are larger in the Alboran region. All figures show 200-, 500-, 1000-, 1500-, and 2000-m isobaths (black contour lines). 
The model dynamics of the Algerian Current is consistent with the behavior reported in earlier studies: Millot (1985) describes the AC as a near-coastal steady flow that becomes unstable around $1^{\circ}-2^{\circ} \mathrm{E}$, generating eddies of both signs although only the anticyclonic ones evolve into mesoscale structures that can detach northward, remaining in the basin for several weeks. More recently, Pessini et al. (2018) found that long-lived anticyclonic eddies predominate in this basin, significantly contributing to the mesoscale activity. This activity decays during the cold seasons, when the AC flows mostly concentrated along the African coast. A recurrent cyclonic deflection is observed in the $\mathrm{AC}$ near $2^{\circ} \mathrm{E}$, giving rise to an anticyclonic gyre in the Gulf of Alicante and an associated front (less defined than the AO front) between Cartagena and the African coast, around $37^{\circ} \mathrm{N}, 0.5^{\circ} \mathrm{E}$. Recent studies by Mason et al. (2013), Pascual et al. (2017), and HernándezCarrasco and Orfila (2018) have reported evidence of this secondary front. In the northern half of the domain, the water transports through the Ibiza and Malloca Channels are strongly affected by the circulation patterns within the Algerian Basin, as already reported by Pinot et al. (2002) and Heslop et al. (2012). By extension, this also conditions the circulation in the Balearic Sea, characterized by the Balearic Current, flowing northeastward along the Balearic Archipelago, and a branch of the northern current, which flows southwestward along the Spanish coast. Our results show that this branch mostly deflects cyclonically, joins the BC in front of the Mallorca coast, and occasionally crosses the Ibiza Channel; conversely, the cited work by Pinot et al. (2002) argues that the water transport through the channel is dominated by the southward flow of the NC.

Mean circulation patterns are also reflected in the spatial distribution of surface MKE, which is concentrated along the paths of the principal currents. The Alboran system and around $0.5^{\circ} \mathrm{W}$, where the AC emerges, show the highest energy amounts exceeding $800 \mathrm{~cm}^{2} \mathrm{~s}^{-2}$ at certain points of the route; the $\mathrm{NC}$ is quite well defined (between 400 and $600 \mathrm{~cm}^{2} \mathrm{~s}^{-2}$ ) and, with less intensity, the Cartagena and Balearic Currents, showing around 300 and $200 \mathrm{~cm}^{2} \mathrm{~s}^{-2}$, respectively.

The variability in the position and occurrence of mesoscale structures is reflected in the time-averaged EKE distribution, which presents a very diffuse pattern. The strongest signal is registered throughout the Alboran region and along the AC system, extending over the southern half of the domain, while in the north, the stability of the $\mathrm{NC}$ is reflected by the negligible EKE signal. A qualitative comparison with a previous work by Pujol and Larnicol (2005) based on the analysis of 11 years of altimetric data for the entire Mediterranean Basin shows that EKE regional distribution displays similar patterns in key areas, such as the
Alboran Sea and south of Sardinia, although our study depicts a wider domain of relevant activity, presumably not detected from satellite measurements. The validation of the ROMSWMED32 solution carried out by Escudier (2015) shows additional comparisons with estimations derived from altimetry, drifter trajectories, and the parent NEMOMED12. Although the values are quite lower for altimetry and NEMOMED12, the spatial distributions from the considered datasets also show similar patterns to those from ROMSWMED32.

\section{b. Simplified LEC and EKE production}

The LEC, focused on the KE components of the energy balance equations, first provides a hint at the amounts of $\mathrm{KE}$ of the mean and eddy flows stored within the WMed region. While the volume-integrated MKE values are around 0.6 PJ, the total EKE amounts to $2.2 \mathrm{PJ}-$ more than 3 times the former. These results can be qualitatively compared to those obtained from von Storch et al. (2012), who present an estimate of the LEC for the World Ocean from a multidecadal simulation at $1 / 10^{\circ}$ resolution: $1.3 \mathrm{EJ}$ of MKE against 3.5 EJ of EKE. Bridging the gap between the considered domains, resolution, and model specifications, the ratio between the amounts of both forms of energy throws a similar result in the WMed region. Another common feature is the regional distribution, showing a MKE concentrated along the main currents, in contrast to the spread distribution of EKE.

Regarding potential energy, we do not consider the APE budgets, since their formulations strongly depend on the choice of a minimum energy reference state of the ocean, which is highly affected by the accuracy of stored data and model resolution. Its application is reserved to the analysis of the mean-eddy flow interactions.

Besides providing an idea of the quantification of the ocean's KE, the LEC equations include energy generation, conversion, and dissipation terms, which can be used as a tool for analyzing the physical mechanisms responsible for maintaining the balance in the WMed. Focusing on the terms involving $\mathrm{KE}$ production, domain-integrated $\mathrm{KE}$ generation and conversion rates display a seasonal nature as might be expected, since transfers between different scales and forms of energy emerge as a response to dynamical mechanisms occurring with more or less intensity throughout the year. Most of the power input into the time-varying circulation stems from the time-varying winds $\left(f_{e} k_{e}\right)$, which are especially strong during cold seasons in the regions of the Alboran Sea and Gulf of Lions. By contrast, the regional distribution of energy transfer from mean winds to MKE $\left(f_{m} k_{m}\right)$ displays a dipole pattern combining areas of positive and negative wind work contributions, which, when integrated over the whole domain, result in a minor contribution from the mean 
winds of at least one order of magnitude lower than the area-integrated $f_{e} k_{e}$.

The LEC scheme formulated in Chen et al. (2014) and used in this study allows for discerning about the locality or nonlocality of the mean eddy flow interactions. This is especially useful in semienclosed domains, as in the case of the western Mediterranean region. For that purpose, we divide our domain into three subregions with their own particular circulation patterns and dynamics, although continuously interacting between them, and with the surrounding waters: the Alboran Sea, Algerian Basin, and northern basin. Energy conversion terms have been considered in these areas separately in order to analyze, through a regional formulation of the LEC, the dominant energy routes and possible interactions between neighboring regions. In the Alboran Sea, barotropic and baroclinic instabilities contribute similarly to EKE generation. While the former can be considered of local origin, nearly half of the EAPE converted into EKE via baroclinic instabilities is injected from the surroundings. In the Algerian Basin, the barotropic conversion route is highly nonlocal and half of the EKE generated through eddy momentum fluxes is injected from outer regions. By contrast, only a small amount of the APE released from the mean flow is transported outside. The largest contribution to the EKE in this subregion derives from EAPE transformations via baroclinic instabilities. APE transformations in the northern basin are significantly nonlocal, since a large amount of EAPE is supplied from outlying regions and converted into EKE. In this sector EKE production via barotropic instabilities (mostly local) results in less than $10 \%$ of the amount generated through baroclinic instabilities.

In general, baroclinic instability is the principal conversion pathway, subtracting EKE from eddy buoyancy work. Higher activity is found around most energetic regions dominated by strong currents and frequent mesoscale activity: north of the Balearic Sea, in front of the African coast, and particularly in both Alboran anticyclonic gyres, showing strong baroclinic conversion on their northern ridges in contrast with the opposite situation found at their southern edges, where EKE is converted into EAPE. This sequence of positive-negative dipoles is also found along currents flowing over sharp bathymetric profile-around the Balearic Islands, south of Sardinia in front of the African coast, in the Gulf of Alicante, or along the path of the NC when crossing the Gulf of Lions-therefore, conversion is presumably driven by interaction with abrupt topography.

\section{c. Flow-topography interaction}

Several mechanisms have been proposed for extracting energy from geostrophic motions toward dissipation involving a forward energy cascade by means of unbalanced submesoscale processes, for example, frontogenesis in the intense density fronts and filaments (Mahadevan and Tandon 2006; Capet et al. 2008; McWilliams 2016), symmetric instability and inertiagravity waves (Ferrari and Wunsch 2009; Thomas et al. 2013), topographic generation of internal gravity waves (Nikurashin et al. 2013; Lamb 2014). More recently, a mechanism consisting of dissipative interaction of the geostrophic flow against bottom topography has been proposed (Molemaker et al. 2015; Gula et al. 2015, 2016). The results of this study suggest that topographic features interact with the flow and induce a dynamical response to restore equilibrium in the form of a conversion between kinetic and potential energy and between the mean and eddy flow. This is noticeable in certain areas of the western Mediterranean Sea-the Alboran Sea, the Algerian Current, the Balearic Archipelago, the Gulf of Alicante or the Northern Current-which are characterized by more or less strong currents flowing along sharp bathymetric slopes, ridges, and other topographic features. On this basis, we suggest a mechanism by means of which energy is cascaded from the geostrophic flow into submesoscale structures via anticyclonic vorticity generation. The sequence consists of a potential vorticity reduction of the impacting flow by bottom frictional torques, followed by current separation over complex topography and the production of negative vorticity that leads to the development of anticyclonic vortices (Molemaker et al. 2015). This is particularly likely to happen in the AC, where the permanent generation of meanders and anticyclonic eddies along the eastward mainstream shows major evidence of topographic negative vorticity generation. Although the solution used in this study shows evidence of the occurrence of such process in this region, it reproduces very weakly the intermediate stages, like the development of bottom pressure torques through pressure anomalies around the obstacles, which would explain the separation of the current from the coast. Furthermore, the model resolution is far from being able to resolve the small-scale processes involved in the dilution of potential vorticity through mixing and dissipation, or the small-scale flow self-organization into larger-scale coherent structures.

A full characterization of these processes is expected to be achieved in forthcoming studies through a set of nested ROMS simulations. Thus, this work constitutes the first step toward an accurate submesoscale characterization of the western Mediterranean Sea.

Acknowledgments. This work has been possible thanks to financial support from Evos (CSIC 201530E067), Morfintra (MINECO/FEDER, CTM2015-66225-C2-2-P), 
and Jerico-Next (EU H2020-INFRAIA-2014, Grant Agreement 654410-425). Evan Mason was partially funded by the Copernicus Marine Environment Monitoring Service (CMEMS) MedSUB project (21-SE-CALL1). We thank Dr. Romain Escudier for providing model simulations. Comments from Prof. J. McWilliams and two anonymous referees are greatly appreciated.

\section{APPENDIX A}

\section{List of Acronyms}

$\begin{array}{ll}\text { AC } & \begin{array}{l}\text { Algerian Current } \\ \text { Adaptive Grid Refinement in Fortran } \\ \text { (AGRIF), version 3.0 }\end{array} \\ \text { AO } & \text { Almeria-Oran } \\ \text { APE } & \text { Available potential energy } \\ \text { AW } & \text { Atlantic water } \\ \text { BC } & \text { Balearic Current } \\ \text { CI } & \text { Centrifugal instability } \\ \text { EAG } & \text { Eastern Anticyclonic Gyre } \\ \text { EAPE } & \text { Eddy available potential energy } \\ \text { EKE } & \text { Eddy kinetic energy } \\ \text { EN4 } & \text { ENACT-ENSEMBLES, version 4 } \\ \text { ENACT } & \text { Enhanced Ocean Data Assimilation } \\ & \quad \text { and Climate Prediction } \\ \text { ENSEMBLES } & \text { Ensemble-Based Predictions of Climate } \\ & \text { Changes and Their Impacts } \\ \text { GHRSST } & \text { Group for High Resolution Sea Surface } \\ & \quad \text { Temperature } \\ \text { KE } & \text { Kinetic energy } \\ \text { KPP } & K \text {-profile parameterization } \\ \text { LEC } & \text { Lorenz energy cycle } \\ \text { L4 } & \text { Level 4 } \\ \text { LMD } & \text { Large-McWilliams-Doney } \\ \text { MAPE } & \text { Mean available potential energy } \\ \text { MKE } & \text { Mean kinetic energy } \\ \text { MW } & \text { Mediterranean water } \\ \text { NC } & \text { Northern Current } \\ \text { PE } & \text { Potential energy } \\ & \end{array}$

RANS ROMS WAG WMed
Reynolds-Averaged Navier-Stokes Regional Oceanic Modeling System Western Anticyclonic Gyre Western Mediterranean Sea

\section{APPENDIX B}

\section{Assessment of Statistical Equilibrium and Model Spinup}

LEC analysis is based on the statistical stationarity of the amounts involved in the energy balance equations. In this regard, two issues must be addressed concerning the model outputs: it is necessary, first, to determine the spinup time needed for the solution to reach stability and, second, to assess whether statistical equilibrium of the energy amounts is maintained over the analyzed period. To this end, the time evolution of volume-integrated EKE and EAPE is computed in each region (Fig. B1). Although the annual cycle has been removed, many other sources of variability involving a wide spectrum of scales can affect the statistical equilibrium of the series: from the small-scale fluctuations emerging from local dynamics to the long-term tendencies stemming from the nonstationarity of atmospheric and boundary forcings. Despite this variability, these plots show that the stability of the model is virtually achieved in the three regions after three years. Beyond this spinup, we can assume a form of statistical equilibrium of the series in the framework of the energy budget equations.

\section{APPENDIX C}

\section{The RANS Equations}

The mathematical concept of EKE strictly arises from the Reynolds-averaged Navier-Stokes (RANS) equations, whose development is based on the Reynolds decomposition of the flow properties [Eq. (2)]. The RANS momentum equations in the $x, y$, and $z$ directions are

$$
\begin{gathered}
\frac{\partial \bar{u}}{\partial t}+\bar{u} \frac{\partial \bar{u}}{\partial x}+\bar{v} \frac{\partial \bar{u}}{\partial y}+\bar{w} \frac{\partial \bar{u}}{\partial z}=-\frac{1}{\rho} \frac{\partial \bar{p}}{\partial x}+\nu\left(\frac{\partial^{2} \bar{u}}{\partial x^{2}}+\frac{\partial^{2} \bar{u}}{\partial y^{2}}+\frac{\partial^{2} \bar{u}}{\partial z^{2}}\right)-\left(\frac{\partial \overline{u^{\prime} u^{\prime}}}{\partial x}+\frac{\partial \overline{u^{\prime} v^{\prime}}}{\partial y}+\frac{\partial \overline{u^{\prime} w^{\prime}}}{\partial z}\right), \\
\frac{\partial \bar{v}}{\partial t}+\bar{u} \frac{\partial \bar{v}}{\partial x}+\bar{v} \frac{\partial \bar{v}}{\partial y}+\bar{w} \frac{\partial \bar{v}}{\partial z}=-\frac{1}{\rho} \frac{\partial \bar{p}}{\partial y}+\nu\left(\frac{\partial^{2} \bar{v}}{\partial x^{2}}+\frac{\partial^{2} \bar{v}}{\partial y^{2}}+\frac{\partial^{2} \bar{v}}{\partial z^{2}}\right)-\left(\frac{\partial \overline{v^{\prime} u^{\prime}}}{\partial x}+\frac{\partial \overline{v^{\prime} v^{\prime}}}{\partial y}+\frac{\partial \overline{v^{\prime} w^{\prime}}}{\partial z}\right), \quad \text { and } \\
\frac{\partial \bar{w}}{\partial t}+\bar{u} \frac{\partial \bar{w}}{\partial x}+\bar{v} \frac{\partial \bar{w}}{\partial y}+\bar{w} \frac{\partial \bar{w}}{\partial z}=-\frac{1}{\rho} \frac{\partial \bar{p}}{\partial z}+\nu\left(\frac{\partial^{2} \bar{w}}{\partial x^{2}}+\frac{\partial^{2} \bar{w}}{\partial y^{2}}+\frac{\partial^{2} \bar{w}}{\partial z^{2}}\right)-\left(\frac{\partial \overline{w^{\prime} u^{\prime}}}{\partial x}+\frac{\partial \overline{w^{\prime} v^{\prime}}}{\partial y}+\frac{\partial \overline{w^{\prime} w^{\prime}}}{\partial z}\right),
\end{gathered}
$$



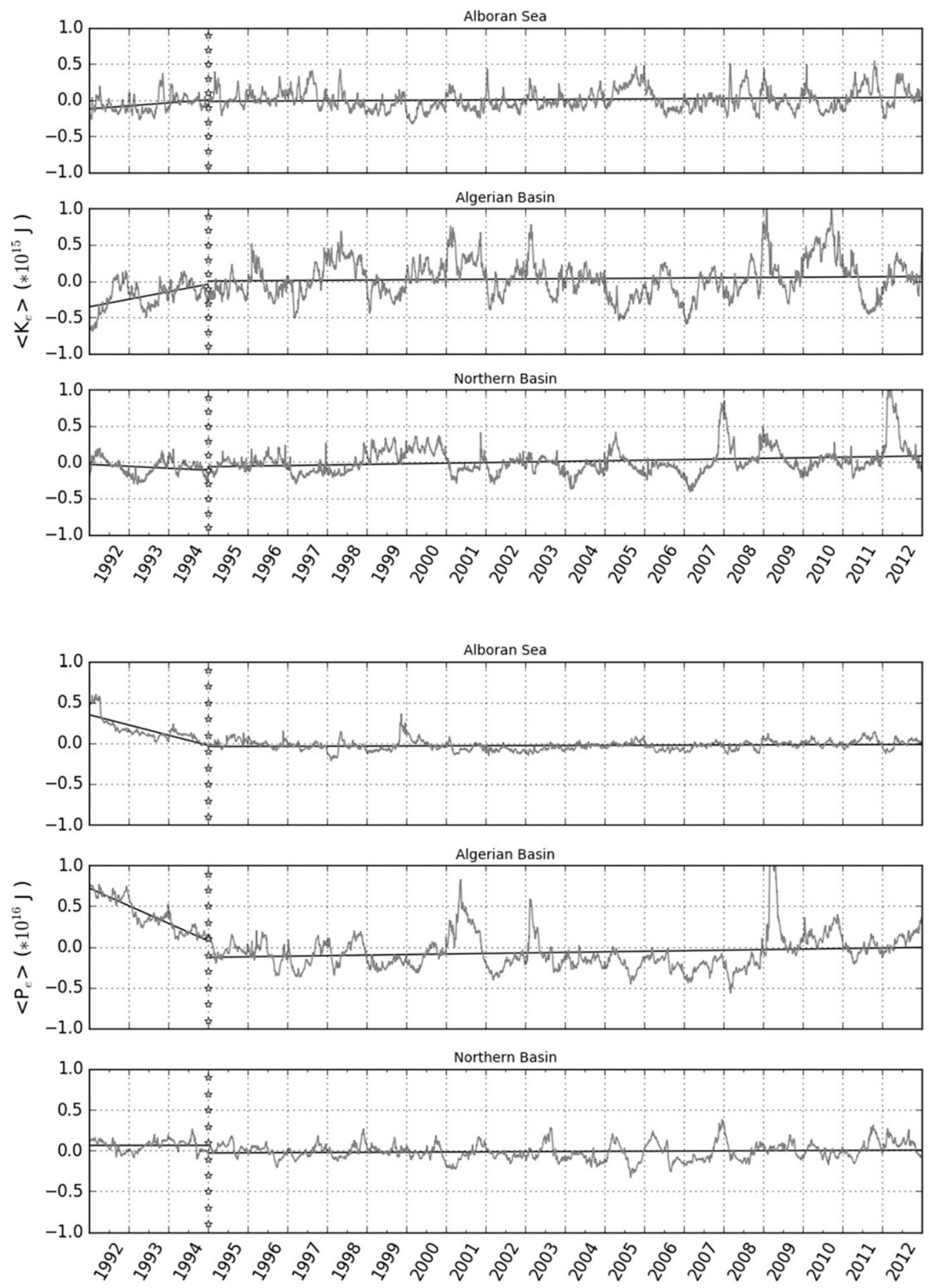

FIG. B1. Time series of the (top) volume-integrated EKE and (bottom) EAPE for each region of the domain. The annual cycle has been removed from the respective series. Linear adjustments (black lines) show the trends of the first three years of the series (1992-94) in comparison with those of the 18-yr remaining period (1995-2012). 
respectively. As the averaged derivatives of the eddy components are zero, the averaged continuity equation is

$$
\frac{\partial \bar{u}}{\partial x}+\frac{\partial \bar{v}}{\partial y}+\frac{\partial \bar{w}}{\partial z}=0
$$

Equations (C1)-(C3) differ from the original NavierStokes in the last terms in parentheses on the rhs, which involve the velocity covariances and represent the Reynolds stresses. Its relevance lies in the fact that the mean turbulent (or eddy) kinetic energy per unit mass $k_{e}$ is defined to be half the trace of the Reynolds stress tensor:

$$
\bar{k}=\frac{1}{2} \overline{\left(u^{\prime} u^{\prime}+v^{\prime} v^{\prime}+w^{\prime} w^{\prime}\right)} .
$$

\section{APPENDIX D}

\section{Notes about Derivation of the KE Balance Equations}

As stated in von Storch et al. (2012) (appendix B), the balance equation of mean kinetic energy [Eq. (8)] is obtained by multiplying the zonal and meridional components of the momentum equations with $\bar{u}$ and $\bar{v}$, summing up and averaging the results over time. To avoid any confusion arising from the time averaging of the tendency terms, here we show the derivation process for these terms.

First, we multiply the tendency terms in the zonal and meridional components of the Navier-Stokes momentum equations by $\bar{u}$ and $\bar{v}$, respectively. Applying the Reynolds decomposition of the flow, we get

$$
\begin{aligned}
& \bar{u} \frac{\partial\left(\bar{u}+u^{\prime}\right)}{\partial t}=\bar{u} \frac{\partial \bar{u}}{\partial t}+\bar{u} \frac{\partial u^{\prime}}{\partial t}, \quad \text { and } \\
& \bar{v} \frac{\partial\left(\bar{v}+v^{\prime}\right)}{\partial t}=\bar{v} \frac{\partial \bar{v}}{\partial t}+\bar{v} \frac{\partial v^{\prime}}{\partial t} .
\end{aligned}
$$

As $\bar{u}$ and $\bar{v}$ are the time averages of $u$ and $v$, respectively, their partial derivatives [the first terms on the rhs of Eqs. (D1) and (D2)] vanish. However, we retain those terms, since we want to achieve an expression that explicitly contains $K_{m}$. Thus, rewriting these terms and summing Eqs. (D1) and (D2) yields

$$
\begin{aligned}
\bar{u} \frac{\partial\left(\bar{u}+u^{\prime}\right)}{\partial t}+\bar{v} \frac{\partial\left(\bar{v}+v^{\prime}\right)}{\partial t}= & \frac{\partial}{\partial t}\left(\frac{\bar{u}^{2}}{2}\right)+\frac{\partial}{\partial t}\left(\frac{\bar{v}^{2}}{2}\right) \\
& +\bar{u} \frac{\partial u^{\prime}}{\partial t}+\bar{v} \frac{\partial v^{\prime}}{\partial t} .
\end{aligned}
$$

The addition of the first two terms on the rhs gives $\left(1 / \rho_{0}\right) \partial K_{m} / \partial t$. Then, time averaging yields

$$
\begin{aligned}
\overline{\bar{u} \frac{\partial\left(\bar{u}+u^{\prime}\right)}{\partial t}+\bar{v} \frac{\partial\left(\bar{v}+v^{\prime}\right)}{\partial t}} & =\frac{1}{\rho_{0}} \frac{\partial K_{m}}{\partial t}+\overline{\bar{u} \frac{\partial u^{\prime}}{\partial t}}+\overline{\bar{v} \frac{\partial v^{\prime}}{\partial t}} \\
& =\frac{1}{\rho_{0}} \frac{\partial K_{m}}{\partial t},
\end{aligned}
$$

as the averaged eddy components are, by definition, zero. Although $\partial K_{m} / \partial t$ is also zero, we retain this term in Eq. (8) in order to maintain the symmetry of the four balance equations.

The same procedure, but multiplying the tendency terms in the zonal and meridional components of the Navier-Stokes momentum equations with $u^{\prime}$ and $v^{\prime}$, respectively, yields the eddy kinetic balance [Eq. (9)].

\section{REFERENCES}

Beuvier, J., and Coauthors, 2012: Spreading of the Western Mediterranean Deep Water after winter 2005: Time scales and deep cyclone transport. J. Geophys. Res., 117, C07022, https:// doi.org/10.1029/2011JC007679.

Capet, X., J. C. McWilliams, M. J. Molemaker, and A. F. Shchepetkin, 2008: Mesoscale to submesoscale transition in the California Current System. Part I: Flow structure, eddy flux, and observational tests. J. Phys. Oceanogr., 38, 29-43, https://doi.org/10.1175/2007JPO3671.1.

Chelton, D. B., R. A. Deszoeke, M. G. Schlax, K. El Naggar, and N. Siwertz, 1998: Geographical variability of the first baroclinic Rossby radius of deformation. J. Phys. Oceanogr., 28, 433-460, https://doi.org/10.1175/1520-0485(1998)028<0433: GVOTFB $>2.0 . \mathrm{CO} ; 2$.

Chen, R., G. R. Flierl, and C. Wunsch, 2014: A description of local and nonlocal eddy-mean flow interaction in a global eddypermitting state estimate. J. Phys. Oceanogr., 44, 2336-2352, https://doi.org/10.1175/JPO-D-14-0009.1.

Debreu, L., C. Vouland, and E. Blayo, 2008: AGRIF: Adaptive grid refinement in Fortran. Comput. Geosci., 34, 8-13, https:// doi.org/10.1016/j.cageo.2007.01.009.

Escudier, R. M. P., 2015: Mesoscale eddies in the western Mediterranean Sea: Characterization and understanding from satellite observations and model simulations. Ph.D. thesis, Universitat de les Illes Balears, 288 pp., http:/hdl.handle.net/ 10803/310417.

- L. Renault, A. Pascual, P. Brasseur, D. Chelton, and J. Beuvier, 2016: Eddy properties in the Western Mediterranean Sea from satellite altimetry and a numerical simulation. J. Geophys. Res. Oceans, 121, 3990-4006, https://doi.org/ 10.1002/2015JC011371.

Ferrari, R., and C. Wunsch, 2009: Ocean circulation kinetic energy: Reservoirs, sources, and sinks. Annu. Rev. Fluid Mech., 41, 253282, https://doi.org/10.1146/annurev.fluid.40.111406.102139.

Gula, J., M. J. Molemaker, and J. C. McWilliams, 2015: Topographic vorticity generation, submesoscale instability and vortex street formation in the Gulf Stream. Geophys. Res. Lett., 42, 4054-4062, https://doi.org/10.1002/2015GL063731.

,$--\ldots$, and — 2016: Topographic generation of submesoscale centrifugal instability and energy dissipation. Nat. Commun., 7, 12811, https://doi.org/10.1038/ncomms12811.

Harrison, D. E., and A. R. Robinson, 1978: Energy analysis of open regions of turbulent flows-Mean eddy energetics of a 
numerical ocean circulation experiment. Dyn. Atmos. Oceans, 2, 185-211, https://doi.org/10.1016/0377-0265(78)90009-X.

Hernández-Carrasco, I., and A. Orfila, 2018: The role of an intense front on the connectivity of the western Mediterranean Sea: The Cartagena-Tenes front. J. Geophys. Res. Oceans, 123, 4398-4422, https://doi.org/10.1029/2017JC013613.

Heslop, E. E., S. Ruiz, J. Allen, J. L. López-Jurado, L. Renault, and J. Tintoré, 2012: Autonomous underwater gliders monitoring variability at "choke points" in our ocean system: A case study in the Western Mediterranean Sea. Geophys. Res. Lett., 39, L20604, https://doi.org/10.1029/2012GL053717.

Huang, R. X., 2005: Available potential energy in the world's oceans. J. Mar. Res., 63, 141-158, https://doi.org/10.1357/ 0022240053693770.

Lamb, K. G., 2014: Internal wave breaking and dissipation mechanisms on the continental slope/shelf. Annu. Rev. Fluid Mech., 46, 231-254, https://doi.org/10.1146/annurevfluid-011212-140701.

Large, W. G., J. C. McWilliams, and S. C. Doney, 1994: Oceanic vertical mixing: A review and a model with a nonlocal boundary layer parameterization. Rev. Geophys., 32, 363-403, https://doi.org/10.1029/94RG01872.

Li, L., A. P. Ingersoll, X. Jiang, D. Feldman, and Y. L. Yung, 2007: Lorenz energy cycle of the global atmosphere based on reanalysis datasets. Geophys. Res. Lett., 34, L16813, https:// doi.org/10.1029/2007GL029985.

Lorenz, E. N., 1955: Available potential energy and the maintenance of the general circulation. Tellus, 7, 157-167, https:// doi.org/10.3402/tellusa.v7i2.8796.

Mahadevan, A., and A. Tandon, 2006: An analysis of mechanisms for submesoscale vertical motion at ocean fronts. Ocean Modell., 14, 241-256, https://doi.org/10.1016/j.ocemod.2006.05.006.

Malanotte-Rizzoli, P., and Coauthors, 2014: Physical forcing and physical/biochemical variability of the Mediterranean Sea: A review of unresolved issues and directions for future research. Ocean Sci., 10, 281-322, https://doi.org/10.5194/os-10-281-2014.

Marchesiello, P., J. C. McWilliams, and A. Shchepetkin, 2003: Equilibrium structure and dynamics of the California Current System. J. Phys. Oceanogr., 33, 753-783, https://doi.org/10.1175/ 1520-0485(2003)33<753:ESADOT>2.0.CO;2.

Mason, E., and A. Pascual, 2013: Multiscale variability in the Balearic Sea: An altimetric perspective. J. Geophys. Res. Oceans, 118, 3007-3025, https://doi.org/10.1002/jgrc.20234.

,-- , and J. C. McWilliams, 2013: High resolution simulations and glider observations in the eastern Alboran Sea (Mediterranean Sea): Implications for vertical velocity estimates. Geophysical Research Abstracts, Vol. 15, Abstract 12311, https://meetingorganizer.copernicus.org/EGU2013/ EGU2013-12311.pdf.

McWilliams, J. C., 2016: Submesoscale currents in the ocean. Proc. Roy. Soc. London, 472A, 20160117, https://doi.org/10.1098/ rspa.2016.0117.

Millot, C., 1985: Some features of the Algerian Current. J. Geophys. Res., 90, 7169-7176, https://doi.org/10.1029/ JC090iC04p07169.

- 1999: Circulation in the western Mediterranean Sea. J. Mar. Syst., 20, 423-442, https://doi.org/10.1016/S0924-7963(98) 00078-5.

Molemaker, M. J., J. C. McWilliams, and W. K. Dewar, 2015: Submesoscale instability and generation of mesoscale anticyclones near a separation of the California Undercurrent. J. Phys. Oceanogr., 45, 613-629, https://doi.org/10.1175/ JPO-D-13-0225.1.
Nikurashin, M., G. K. Vallis, and A. Adcroft, 2013: Routes to energy dissipation for geostrophic flows in the Southern Ocean. Nat. Geosci., 6, 48-51, https://doi.org/10.1038/ngeo1657.

Oort, A. H., L. A. Anderson, and J. P. Peixoto, 1994: Estimates of the energy cycle of the oceans. J. Geophys. Res., 99, 76657665, https://doi.org/10.1029/93JC03556.

Pascual, A., and Coauthors, 2017: A multiplatform experiment to unravel meso- and submesoscale processes in an intense front (AlborEx). Front. Mar. Sci., 4, 39, https://doi.org/10.3389/ fmars.2017.00039.

Pessini, F., A. Olita, Y. Cotroneo, and A. Perilli, 2018: Mesoscale eddies in the Algerian Basin: Do they differ as a function of their formation site? Ocean Sci., 14, 669-688, https://doi.org/ 10.5194/os-14-669-2018.

Pinardi, N., and E. Masetti, 2000: Variability of the large scale general circulation of the Mediterranean Sea from observations and modelling: A review. Palaeogeogr. Palaeoclimatol. Palaeoecol., 158, 153-173, https://doi.org/10.1016/S0031-0182(00) 00048-1.

Pinot, J.-M., J. L. López-Jurado, and M. Riera, 2002: The CANALES experiment (1996-1998). Interannual, seasonal, and mesoscale variability of the circulation in the Balearic Channels. Prog. Oceanogr., 55, 335-370, https://doi.org/10.1016/S00796611(02)00139-8.

Pope, S. B., 2000: Turbulent Flows. Cambridge University Press, $771 \mathrm{pp}$.

Pujol, M. I., and G. Larnicol, 2005: Mediterranean sea eddy kinetic energy variability from 11 years of altimetric data. J. Mar. Syst., 58, 121-142, https://doi.org/10.1016/j.jmarsys.2005.07.005.

Reid, R. O., B. A. Elliott, and D. B. Olson, 1981: Available potential energy: A clarification. J. Phys. Oceanogr., 11, 15-29, https://doi.org/10.1175/1520-0485(1981)011<0015:APEAC> 2.0.CO;2.

Renault, L., T. Oguz, A. Pascual, G. Vizoso, and J. Tintoré, 2012: Surface circulation in the Alborán Sea (western Mediterranean) inferred from remotely sensed data. J. Geophys. Res., 117, C08009, https://doi.org/10.1029/2011JC007659.

—, M. J. Molemaker, J. C. McWilliams, A. F. Shchepetkin, F. Lemarié, D. Chelton, S. Illig, and A. Hall, 2016: Modulation of wind work by oceanic current interaction with the atmosphere. J. Phys. Oceanogr., 46, 1685-1704, https://doi.org/ 10.1175/JPO-D-15-0232.1.

Rio, M., A. Pascual, P. Poulain, M. Menna, B. Barceló, and J. Tintoré, 2014: Computation of a new mean dynamic topography for the Mediterranean Sea from model outputs, altimeter measurements and oceanographic in situ data. Ocean Sci., 10, 731-744, https://doi.org/10.5194/os-10-731-2014.

Robinson, A. R., W. G. Leslie, A. Theocharis, and A. Lascaratos, 2001: Mediterranean Sea circulation. Encyclopedia of Ocean Sciences, J. H. Steele, S. A. Thorpe, and K. K. Turekian, Eds., Academic Press, 1689-1705, https://doi.org/10.1006/rwos.2001.0376.

Sanz, J. L., M. Esteras, P. Herranz, C. Palomo, and N. Sandoval, 1991: Prospeccion Geofísica del Estrecho de Gibraltar (Resultados del Programa Hercules, 1980-1983). Publicaciones Especiales del Instituto Español de Oceanografía, Vol. 7, Ministerio de Agricultura, Pesca y Alimentación, 48 pp.

Shchepetkin, A. F., and J. C. McWilliams, 2005: The regional oceanic modeling system (ROMS): A split-explicit, free-surface, topography-following-coordinate oceanic model. Ocean Modell., 9, 347-404, https://doi.org/10.1016/j.ocemod.2004.08.002.

$\longrightarrow$, and - 2009: Correction and commentary for "Ocean forecasting in terrain-following coordinates: Formulation and skill assessment of the regional ocean modeling system" by 
Haidvogel et al., J. Comp. Phys. 227, pp. 3595-3624. J. Comput. Phys., 228, 8985-9000, https://doi.org/10.1016/ j.jcp.2009.09.002.

Smith, W. H., and D. T. Sandwell, 1997: Global sea floor topography from satellite altimetry and ship depth soundings. Science, 277, 1956-1962, https://doi.org/10.1126/science.277.5334.1956.

Sorgente, R., A. Olita, P. Oddo, L. Fazioli, and A. Ribotti, 2011: Numerical simulation and decomposition of kinetic energy in the Central Mediterranean: Insight on mesoscale circulation and energy conversion. Ocean Sci., 7, 503-519, https://doi.org/ 10.5194/os-7-503-2011.

Thomas, L. N., J. R. Taylor, R. Ferrari, and T. M. Joyce, 2013: Symmetric instability in the Gulf Stream. Deep-Sea Res. II, 91, 96-110, https://doi.org/10.1016/j.dsr2.2013.02.025.
Vargas-Yáñez, M., F. Plaza, J. García-Lafuente, T. Sarhan, J. M. Vargas, and P. Vélez-Belchi, 2002: About the seasonal variability of the Alboran Sea circulation. J. Mar. Syst., 35, 229248, https://doi.org/10.1016/S0924-7963(02)00128-8.

von Storch, J.-S., C. Eden, I. Fast, H. Haak, D. HernándezDeckers, E. Maier-Reimer, J. Marotzke, and D. Stammer, 2012: An estimate of the Lorenz energy cycle for the World Ocean based on the STORM/NCEP simulation. J. Phys. Oceanogr., 42 , 2185-2205, https://doi.org/10.1175/ JPO-D-12-079.1.

Wu, Y., Z. Wang, and C. Liu, 2017: On the response of the Lorenz energy cycle for the Southern Ocean to intensified westerlies. J. Geophys. Res. Oceans, 122, 2465-2493, https://doi.org/ 10.1002/2016JC012539. 